\title{
Tijuana ante el confinamiento social impuesto por la COVID 19: habitabilidad de las viviendas, entorno urbano y condiciones económicas de los hogares
}

\author{
Tijuana faced with the social confinement \\ imposed by COVID 19: habitability of homes, urban \\ environment and economic conditions of homes
}

\author{
Gerardo Ordóñez Barba
}

\begin{abstract}
Resumen
El principal objetivo es presentar los resultados de un estudio exploratorio en el que se aplicó un cuestionario sobre las condiciones de habitabilidad de las viviendas y del entorno urbano ante el confinamiento social provocado por la COVID 19 en Tijuana. Se parte del supuesto de que los efectos de la principal medida de contención de la pandemia, el "quédate en casa", son más perjudiciales en hogares que residen en viviendas con peores condiciones de habitabilidad y entornos urbanos menos consolidados. El cuestionario incluyó, además de las dimensiones que tradicionalmente se emplean en el estudio de la habitabilidad, diversos reactivos sobre las implicaciones del confinamiento en las viviendas, al concentrar actividades que normalmente se realizan fuera de ella, como las laborales o educativas, así como sus impactos en las condiciones y los problemas económicas de las familias. Los resultados demuestran que, si bien las condiciones de habitabilidad de las viviendas estudiadas en Tijuana son en su mayoría aceptables, el confinamiento ha evidenciado mayores efectos negativos en viviendas de menores dimensiones y ubicadas en colonias populares o que fueron identificadas como prioritarias por su grado de vulnerabilidad social ante la COVID 19.
\end{abstract}

Palabras clave: covid 19, confinamiento, habitabilidad de las viviendas, entorno urbano, vulnerabilidad social, desigualdad social

\begin{abstract}
The main objective is to present the results of an exploratory study in which a questionnaire was applied on the habitability conditions of homes and the urban environment in the face of social confinement caused by COVID 19 in Tijuana. It is assumed that the effects of the main measure of containment of the pandemic, the "stay at home", are more harmful in households that reside in houses with worse living conditions and less consolidated urban environments. The questionnaire included, in addition to the dimensions that are traditionally used in the study of habitability, various items on the implications of confinement in homes by concentrating activities that are normally carried out outside it, such as work or educational activities, as well as their impacts on the economic conditions and problems of families. The results show that, although the habitability conditions of the homes studied in Tijuana are mostly acceptable, the confinement has shown greater negative effects in homes of smaller dimensions and located in popular neighborhoods or that were identified as priority due to their degree of social vulnerability to COVID 19.
\end{abstract}

Keywords: covid 19, confinement, habitability of the houses, urban environment, social vulnerability, social inequality

- Profesor-investigador de El Colegio de la Frontera Norte desde 1990, actualmente director del Departamento de Estudios de Administración Pública. Miembro del sNI, nivel III. El autor agradece los comentarios y sugerencias de dos dictaminadores anónimos. Esta investigación se desarrolló en el marco del proyecto "Condiciones de habitabilidad de las viviendas ante el 'distanciamiento social' impuesto por el COVID-19" coordinado por la Dra.Alicia Ziccardi. Una versión anterior de este trabajo se encuentra en etapa de dictaminación para su posible publicación en UNAM-IIS (Ordóñez, 2020). Orcid: 0000-0003-34985808 / ordonez@colef.mx

Fecha de recepción: I 2 de julio de 2020. Fecha de aceptación: 5 de agosto de 2020. 
Introducción

Tijuana ha sido históricamente uno de los principales puntos de cruce fronterizos entre México y Estados Unidos, lo cual le ha permitido combinar altas tasas de crecimiento poblacional con una intensa y diversificada actividad económica, lo que la ha convertido en un polo de atracción, tanto para la migración nacional y extranjera que pretende cruzar al vecino país, como para las personas que encuentran en esta ciudad un lugar de residencia permanente. Solo por mencionar un dato, durante todo el siglo xx la población en Tijuana creció a un ritmo promedio del 8.7\% anual (Alegría y Ordóñez, 2005). Aunque se ha moderado la dinámica poblacional en lo que va del presente siglo, la tasa anual de crecimiento en el municipio $(1.76 \%$ en promedio entre 2000 y 2020) se ha mantenido por encima de la media nacional (que ha caído de $1.27 \%$ a $0.94 \%$ en el mismo periodo). No obstante, este dinamismo económico y social no se ha visto acompañado con las inversiones en equipamientos, infraestructura y servicios públicos necesarios para lograr un desarrollo urbano

ordenado, funcional, seguro y socialmente equitativo... [lo cual, además de imponer] restricciones al crecimiento económico, reduce significativamente los niveles de bienestar de amplios sectores de la población e incrementa los riesgos de catástrofes en muchos asentamientos humanos (Alegría y Ordóñez, 2005, p. 16).

Este diagnóstico resulta particularmente pertinente para el escenario que se viene perfilando para la ciudad en torno a la pandemia por Covid 19, sobre todo a partir del establecimiento de la Jornada Nacional de Sana Distancia (Secretaría de Salud, 2020a) y la declaración de Emergencia Sanitaria (Consejo de Salubridad General, 2020) el 23 y 30 de marzo de 2020, respectivamente, cuando se determinaron 
Tijuana ante el confinamiento social impuesto por la coviD- 19: habitabilidad de las viviendas, entorno urbano y condiciones económicas en los hogares

las primeras medidas de distanciamiento y confinamiento social. Como veremos en los apartados 2 y 3 , Tijuana ha venido registrando una de las mayores tasas de infectados y muertes por covid en el país, y lo ha venido enfrentando con una infraestructura médica igualmente deficitaria.

Aunque desconocemos en qué medida se intersectan la marginalidad urbana y los efectos sociales de la crisis sanitaria, podemos suponer que los sectores sociales con peores condiciones de vivienda, infraestructura urbana, ingresos y salud (tanto por desprotección como por padecimientos crónicos), entre otros indicadores, como la edad (adultos mayores) y el género (hombres y mujeres), son los que sufren o sufrirán las peores consecuencias de la pandemia, sea por contagio, por pérdida de su fuente de ingresos o por las condiciones impuestas por el confinamiento social.

En este contexto, el llamado de "Quédate en casa", ${ }^{1}$ como la principal medida de contención de la pandemia, ha

I. Esta medida comenzó a promoverse el 23 de marzo de 2020 como parte de la Jornada Nacional de Sana Distancia, pero estaba especialmente orientada a personas mayormente vulnerables ante la covid (mayores de edad, personas con padecimientos crónicos, obesidad, mujeres embarazadas), o que mostraban síntomas de contagio (Secretaría de Salud, 2020a); posteriormente fue incluida entre las acciones extraordinarias establecidas en la declaración de emergencia sanitaria (Consejo de Salubridad General, 2020), el 30 de marzo de 2020, bajo el concepto de "resguardo domiciliario corresponsable", y se hizo extensivo a toda la población que no realiza actividades esenciales, y entendiéndolo como "la limitación voluntaria de movilidad, permaneciendo en el domicilio particular o sitio distinto al espacio público, el mayor tiempo posible" (fracción iv del artículo primero), pero considerándolo de aplicación estricta "a toda persona mayor de 60 años de edad, estado de embarazo o puerperio inmediato, o con diagnóstico de hipertensión arterial, diabetes mellitus, enfermedad cardíaca o pulmonar crónicas, inmunosupresión (adquirida o provocada), insuficiencia renal o hepática, independientemente de si su actividad laboral se considera esencial" (fracción $\checkmark$ del artículo primero) (Secretaría de Salud, 2020b). En estos instrumentos se establecieron, junto con el confinamiento social, la suspensión de clases y actividades no esenciales, la cancelación de eventos masivos, el alejamiento físico (sana distancia), el lavado de manos, el estornudo de etiqueta y la protección de los adultos mayores. La Jornada Nacional de Sana Distancia concluyó el 3I de mayo, y a partir del I de junio de 2020 se inicia "La nueva normalidad", una etapa en la que se pretende una apertura gradual de actividades a través de un semáforo epidemiológico (Secretaría de Salud, 2020c). 
tenido afectaciones entre las tijuanenses y los tijuanenses respecto de problemáticas derivadas de la habitabilidad de sus viviendas, la calidad del entorno urbano y su capacidad económica, por lo que resulta de particular importancia la aplicación del cuestionario denominado "Condiciones de habitabilidad de las viviendas ante el 'distanciamiento social' impuesto por la covid-19", cuyo levantamiento se inició el 25 de abril (Ziccardi et al., 2020, p. 2); es decir, 32 días después de haberse declarado las primeras medidas de confinamiento. Los resultados que presentaremos en el apartado cuatro de este trabajo corresponden a los cuestionarios levantados en Tijuana al corte del pasado 31 de mayo, pero antes de ello se ofrecerán, en las primeras tres secciones, algunas consideraciones sobre la aproximación teórico-metodológica del estudio; el contexto de Tijuana en términos socioeconómicos, habitacionales y de capacidad de la infraestructura hospitalaria, y las dimensiones y los efectos de la pandemia en la sociedad tijuanense. Al final, en el quinto apartado, presentaremos a manera de conclusiones una relación de las principales acciones implementadas por los gobiernos locales y algunas de las propuestas que se manifestaron en las respuestas del cuestionario para apoyar en la mitigación de los impactos sociales, económicos y sanitarios de la covid en la ciudad.

\section{Consideraciones teórico-metodológicas de estudio}

La aproximación conceptual y metodológica de este trabajo surge del estudio que lideró la doctora Alicia Ziccardi, y que tuvo como uno de sus principales instrumentos el cuestionario denominado "Condiciones de habitabilidad de las viviendas ante el 'distanciamiento social' impuesto por la Covid-19”, el cual fue diseñada por un grupo de investigadores e investigadoras y profesores y profesoras del Instituto de Investigaciones Sociales, la Facultad de Arquitectura,

\section{6}


Tijuana ante el confinamiento social impuesto por la coviD- 19: habitabilidad de las viviendas, entorno urbano y condiciones económicas en los hogares

el Centro Regional de Investigaciones Multidisciplinarias y el Programa Universitario de Estudios del Desarrollo de la UNAM. Su objetivo fue:

conocer los efectos que tiene el "distanciamiento social" en las familias mexicanas, de acuerdo con las condiciones de la vivienda y el entorno urbano en el que se localizan, a fin de elaborar propuestas que permitan enfrentar en las mejores condiciones posibles esta difícil situación sanitaria, económica y social (Ziccardi et al., 2020, p. I).

El estudio en cuestión parte de una conceptualización muy próxima a la que plantea ONU-Hábitat, al considerar que las condiciones de habitabilidad de las viviendas y de su ubicación no solo determinan la calidad de vida o el bienestar de las personas y sus familias, sino también posibilitan el acceso efectivo a diversos derechos sociales:

Las condiciones de habitabilidad de una vivienda determinan, en gran medida, la calidad de vida de las personas que residen en ella. Una vivienda adecuada se considera clave para promover el bienestar, aliviar la pobreza, impulsar la equidad, proteger la vida y la salud de sus ocupantes [,] así como para brindar seguridad y protección física.Además, su ubicación puede contribuir a hacer efectivos otros derechos como el acceso a la educación, la salud y el trabajo y, en general, favorece el desarrollo y mejoramiento de las capacidades e intereses individuales y colectivos (onU-Hábitat, 2018, p. I34).

Como se explica en el informe preliminar del estudio coordinado por Ziccardi et al. (2020), estas cualidades de las viviendas tienden a hacerse más evidentes en situaciones de reclusión, como la que ha provocado la pandemia por COVID 19:

La experiencia de confinamiento en el interior de las viviendas expresa y amplifica las desigualdades estructurales que existen en estas ciudades 
y las limitaciones que se observan para hacer efectivo el derecho a la salud, a la educación, a la vivienda, al espacio público y al trabajo[,] los cuales como ha quedado descubierto con la pandemia están interrelacionados. En términos generales, puede afirmarse que la experiencia de confinamiento adquiere características más críticas en las viviendas con peores condiciones de habitabilidad y es relativamente mejor en aquellas que tienen características materiales y espacios apropiados al tipo de familia que las habita (Ziccardi et al., 2020, p. 2).

Siguiendo con esta perspectiva, en el cuestionario se incluyeron, además de las dimensiones que tradicionalmente se emplean en el estudio de la habitabilidad de las viviendas y del entorno urbano, diversos reactivos que buscan indagar sobre las implicaciones del confinamiento, al concentrar en la vivienda actividades que en condiciones normales se realizan fuera ella, como las laborales, educativas y de esparcimiento. Otra dimensión que también fue considerada alude a las condiciones económicas de las familias y los problemas que enfrentan para cubrir pagos o adeudos. En el cuadro 1 se sintetizan las variables y los indicadores considerados en el cuestionario en función del tipo de dimensión y componente a que están asociados. 
Tijuana ante el confinamiento social impuesto por la coviD- 19: habitabilidad de las viviendas, entorno urbano y condiciones económicas en los hogares

Cuadro 1. Dimensiones, componentes y variables consideradas en el estudio sobre "Condiciones de habitabilidad de las viviendas ante el 'distanciamiento social' impuesto por la COVID-19"

\begin{tabular}{|c|c|c|}
\hline Dimensiones & Componentes & Variables / Indicadores \\
\hline \multirow{13}{*}{ 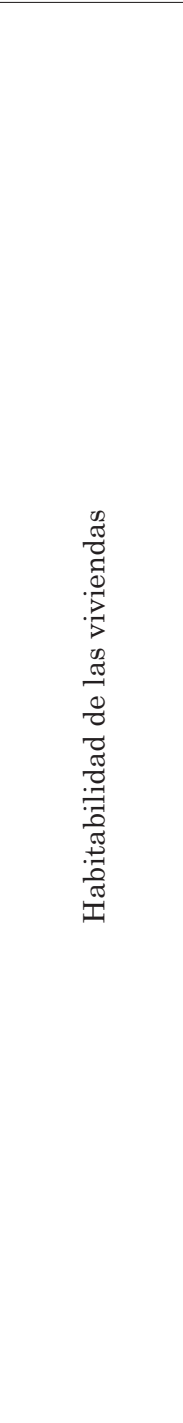 } & $\begin{array}{l}\text { Características del } \\
\text { hogar }\end{array}$ & $\begin{array}{l}\text { Número de miembros; Estructura de } \\
\text { edades; Número de miembros que } \\
\text { trabajan; Número de miembros que } \\
\text { estudian y en qué niveles educativos }\end{array}$ \\
\hline & Tipo de vivienda & $\begin{array}{c}\text { Casa sola, en fraccionamiento o } \\
\text { colonia popular; Departamento; } \\
\text { Vecindad }\end{array}$ \\
\hline & $\begin{array}{c}\text { Tipo de tenencia de } \\
\text { la vivienda }\end{array}$ & $\begin{array}{c}\text { Vivienda propia (pagada o se está } \\
\text { pagando); Rentada; Prestada }\end{array}$ \\
\hline & Dimensiones & Superficie de construcción en $\mathrm{m}^{2}$ \\
\hline & Espacios suficientes & Número de cuartos \\
\hline & y adecuados & Patio, Jardín, Balcón, Ventanas \\
\hline & $\begin{array}{l}\text { Instalaciones } \\
\text { sanitarias }\end{array}$ & Número de baños \\
\hline & Servicios en la & Agua conectada a la red pública y \\
\hline & vivienda & $\begin{array}{l}\text { frecuencia de la provisión (todos o } \\
\text { algunos días); Drenaje }\end{array}$ \\
\hline & $\begin{array}{l}\text { Servicios externos a } \\
\text { la vivienda }\end{array}$ & $\begin{array}{l}\text { Recolección de basura } \\
\text { Seguridad pública }\end{array}$ \\
\hline & $\begin{array}{l}\text { Calidad } \\
\text { constructiva de la } \\
\text { vivienda }\end{array}$ & $\begin{array}{c}\text { Materiales de construcción: Bloque, } \\
\text { Ladrillos, Madera, Otros }\end{array}$ \\
\hline & $\begin{array}{l}\text { Actividades en la } \\
\text { vivienda }\end{array}$ & $\begin{array}{l}\text { Trabajar en línea; Aprender en casa; } \\
\text { Tareas domésticas; Ver televisión; } \\
\text { Ver contenido en Netflix, Amazon, } \\
\text { Claro; Leer libros, periódicos o } \\
\text { revistas; Hacer gimnasia; Juegos de } \\
\text { mesa y juegos por Internet }\end{array}$ \\
\hline & $\begin{array}{l}\text { Distribución de } \\
\text { actividades y tareas } \\
\text { de cuidado por sexo }\end{array}$ & $\begin{array}{l}\text { Trabajo doméstico; Apoyo a tareas } \\
\text { escolares; Compra de alimentos; } \\
\text { Cuidado de niños y/o adultos } \\
\text { mayores; Cuidado de enfermos por } \\
\text { covid-19; Cuidado de personas con } \\
\text { otras enfermedades }\end{array}$ \\
\hline
\end{tabular}




\begin{tabular}{|c|c|c|}
\hline Dimensiones & Componentes & Variables / Indicadores \\
\hline 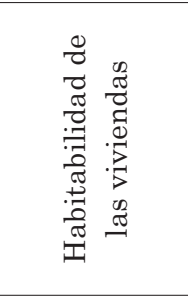 & $\begin{array}{c}\text { Principales } \\
\text { problemas } \\
\text { familiares ante el } \\
\text { confinamiento }\end{array}$ & $\begin{array}{l}\text { Realizar actividad laboral; Cumplir } \\
\text { con la escuela en casa; Proveer } \\
\text { de alimentos; Crear condiciones } \\
\text { de salubridad; Compartir la(s) } \\
\text { computadora(s); Compartir el mismo } \\
\text { espacio; No salir a caminar y hacer } \\
\text { deporte; Cuidado de las mascotas }\end{array}$ \\
\hline 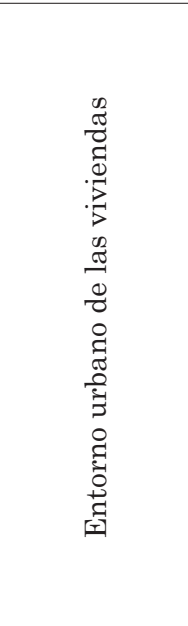 & $\begin{array}{c}\text { Cercanía a espacios } \\
\text { públicos } \\
\text { Cercanía a } \\
\text { establecimientos } \\
\text { hospitalarios } \\
\text { Cercanía a } \\
\text { comercios } \\
\text { Convivencia vecinal }\end{array}$ & $\begin{array}{l}\text { Plaza o parque; Centro cultural o } \\
\text { deportivo; Banquetas } \\
\text { Hospitales públicos; Clínicas de IMss } \\
\text { o Issste; Hospitales privados; Cruz } \\
\text { Roja; Centro de Salud } \\
\text { Mercados, tiendas de abarrotes, oxxo } \\
\text { u otro tipo, supermercados } \\
\text { Actividades de los vecinos y vecinas: } \\
\text { Realizan reuniones para hablar } \\
\text { de la contingencia; Atienden las } \\
\text { necesidades de adultos mayores } \\
\text { que viven solos; Hacen reuniones } \\
\text { sociales; Ponen música en volumen } \\
\text { alto; Salen frecuentemente al espacio } \\
\text { público o a la calle }\end{array}$ \\
\hline 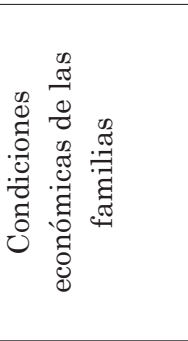 & $\begin{array}{c}\text { Ingresos } \\
\text { Dificultades para } \\
\text { cubrir pagos o } \\
\text { adeudos }\end{array}$ & $\begin{array}{l}\text { Número de miembros que trabajan } \\
\text { Lugar de trabajo } \\
\text { Número de perceptores de ingresos } \\
\text { Pago de hipoteca de la vivienda; } \\
\text { Pago de renta } \\
\text { Pago de créditos o deudas; Pago } \\
\text { de colegiaturas; Pago de servicios; } \\
\text { Cuota de mantenimiento }\end{array}$ \\
\hline
\end{tabular}

Fuente: Elaboración propia sobre la base del cuestionario "Condiciones de habitabilidad de las viviendas ante el 'distanciamiento social' impuesto por el Covid-19” (Ziccardi et al., 2020, p. 37).

El cuestionario fue implementado con el método de bola de nieve y aplicado a través de Internet y telefónicamente mediante Whatsapp. Esto implica que solo se pudo contactar y aplicar a la población que tiene alguna forma de

\section{0}


Tijuana ante el confinamiento social impuesto por la coviD- 19: habitabilidad de las viviendas, entorno urbano y condiciones económicas en los hogares

conectividad a Internet. El estudio se llevó a cabo en las zonas metropolitanas de la Ciudad de México, Guadalajara y Monterrey, así como en las ciudades de Cuernavaca, Toluca, Mérida, Ciudad Juárez y Tijuana (Ziccardi et al., 2020). En Tijuana hubo 271 personas mayores de edad que contestaron el cuestionario al corte del pasado 31 de mayo, de las cuales el $68 \%$ fue mujeres y el $87 \%$ se ubicó en un rango de edad de entre 20 y 60 años.

La muestra alcanzada en Tijuana no garantiza representatividad de todos los sectores sociales y habitacionales de la ciudad, pues hay subrepresentación de los sectores sociales menos favorecidos. Por ello, debemos considerar los resultados del estudio con un alcance exploratorio. No obstante, como puede apreciarse en el mapa 1, por lo menos las ubicaciones de las viviendas de las 254 personas (93.7\% del total) que respondieron adecuadamente a la pregunta sobre el nombre de la colonia en que viven se distribuyen de manera dispersa en 123 colonias y por diferentes zonas de la ciudad, lo cual permite contar con un panorama razonablemente amplio de la problemática en estudio. 
Mapa 1. Distribución de las viviendas por colonia de quienes respondieron el cuestionario "Condiciones de habitabilidad de las viviendas ante el 'distanciamiento social' impuesto por la COVID-19"

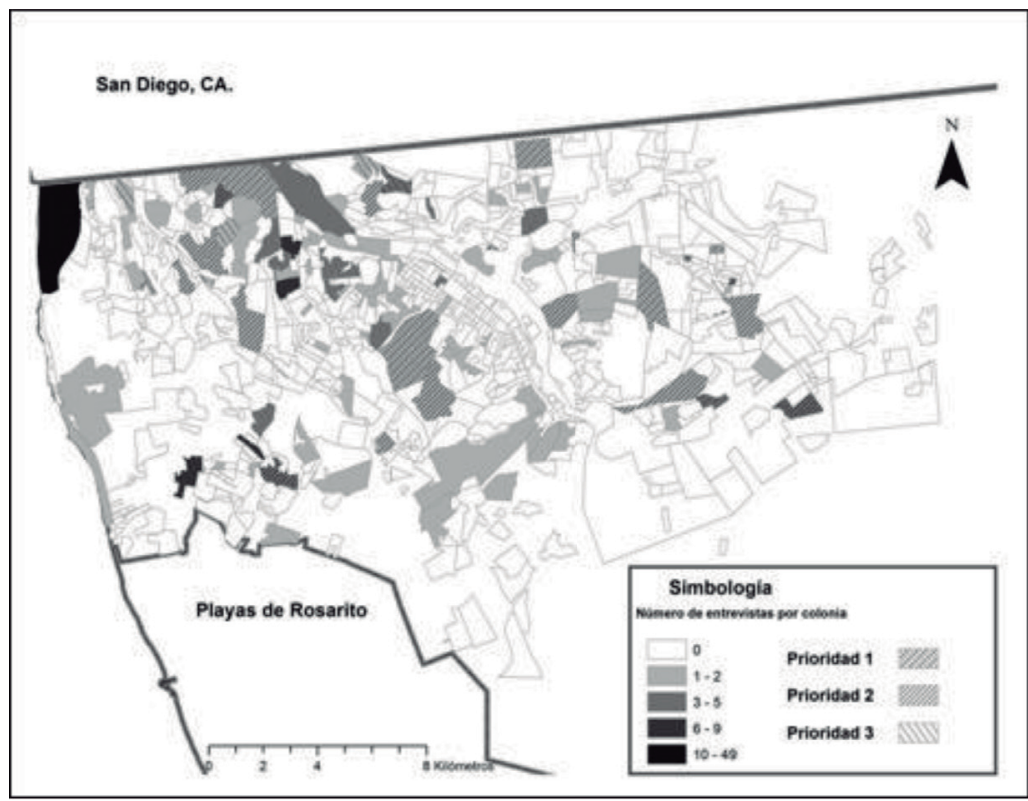

Nota: De las 123 colonias que surgen de la base de datos del cuestionario UNAM-IIS (2020), 36 coinciden con las colonias que fueron identificadas por el estudio "Vulnerabilidad social a la Covid-19 en Tijuana, Baja California (versión 2)” (Sánchez, Morales y Lares, 2020b), con alguno de los tres niveles de prioridad (realzados en el mapa con entramados), que definieron para fines de atención por parte de las autoridades locales. Fuente: Elaborado por la maestra Angélica Zambrano Gil sobre la base del mapa de colonias del IMPLAN (2014), la lista de colonias de la muestra del cuestionario UNAM-IIS (2020) y la lista de colonias prioritarias definidas en Sánchez, Morales y Lares (2020b).

Por otra parte, como se explica en la nota al pie del mapa 1, de acuerdo con el documento de política "Vulnerabilidad social a la Covid-19 en Tijuana, Baja California (versión 2)", dentro de las colonias de nuestra muestra hay 36 que fueron identificadas con algún grado de prioridad; es decir, 
Tijuana ante el confinamiento social impuesto por la coviD- 19: habitabilidad de las viviendas, entorno urbano y condiciones económicas en los hogares

que presentan alta vulnerabilidad social a la COVID- $19^{2}$ y un elevado número de llamadas Covid-19 registradas en la base de datos de Telesalud, que es el teléfono de atención a personas que solicitan algún tipo de apoyo por la pandemia (Sánchez, Morales y Lares, 2020b, p. 6). De acuerdo con la base de datos del cuestionario, en estas colonias se ubica casi el $24 \%$ del total de las viviendas de la muestra, lo que en términos absolutos significa que 64 hogares residen en colonias con prioridad 1, 2 o 3. Para fines de los análisis estadísticos, se hará la distinción de los resultados tomando en cuenta las colonias prioritarias o no, así como a tres tipos de viviendas: casas en colonias consolidadas o en fraccionamientos, casas en colonias populares y departamentos en condominio, unidad habitacional o vecindad.

\section{Tijuana como caso de estudio: condiciones socioeconómicas, habitacionales y de capacidad de la infraestructura hospitalaria}

De acuerdo con la Encuesta Intercensal 2015 (INEGI, 2015), Tijuana ocupa el tercer lugar entre los municipios más poblados de México, solo por debajo de Iztapalapa, en la Ciudad de México, y de Ecatepec de Morelos en el estado de México. Los datos de la estructura poblacional muestran que la distribución entre hombres y mujeres prácticamente se divide a partes iguales para el total, pero en las edades más avanzadas (principalmente a partir de los 55 años) las mujeres comienzan a ser mayoría. Respecto de la estructura por edades, claramente la sociedad tijuanense es relativamente joven, solo el $7.5 \%$ de la población tiene 60 años o

2. El índice de vulnerabilidad de este estudio combinó la escala de AGEB, con datos censales de 2010, variables poblacionales (mayores de 65 y menores de II años, población de 15 años o más sin escolaridad, jefatura femenina, población migrante y hogares indígenas), de vivienda (donde solo uno de los cuartos se usa para dormir, sin agua en la vivienda o en el lote, y sin refrigerador ni lavadora), y de densidad poblacional (Sánchez, Morales y Lares, 2020a, pp. 7-9). 
más (a escala nacional esta proporción llega al 10.5\%), lo cual podría ser una ventaja en el contexto de la pandemia y la vulnerabilidad asociada a la edad, pero, como veremos en la sección siguiente, esta situación no ha seguido el patrón esperado.

Cuadro 2. Población total en viviendas particulares habitadas en Tijuana por grupos quinquenales de edad según sexo, 2015

\begin{tabular}{|c|c|c|c|c|c|c|}
\hline \multirow{2}{*}{$\begin{array}{c}\text { Grupos } \\
\text { quinquenales } \\
\text { de edad }\end{array}$} & \multicolumn{3}{|c|}{ Absolutos } & \multicolumn{3}{|c|}{ Porcentajes } \\
\hline & 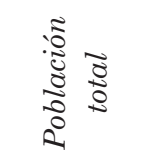 & 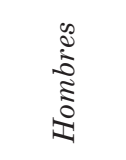 & 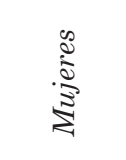 & 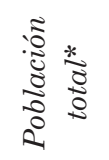 & 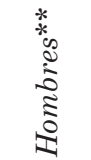 & 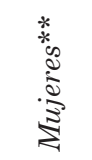 \\
\hline Total & $1,641,570$ & 816,738 & 824,832 & 100.00 & 49.75 & 50.25 \\
\hline 00-04 años & 140,432 & 71,464 & 68,968 & 8.55 & 50.89 & 49.11 \\
\hline 05-09 años & 150,155 & 76,505 & 73,650 & 17.70 & 50.95 & 49.05 \\
\hline 10-14 años & 153,033 & 77,096 & 75,937 & 27.02 & 50.38 & 49.62 \\
\hline 15-19 años & 146,966 & 73,777 & 73,189 & 35.98 & 50.20 & 49.80 \\
\hline 20-24 años & 150,579 & 75,651 & 74,928 & 45.15 & 50.24 & 49.76 \\
\hline 25-29 años & 138,569 & 67,155 & 71,414 & 53.59 & 48.46 & 51.54 \\
\hline 30-34 años & 136,364 & 68,432 & 67,932 & 61.90 & 50.18 & 49.82 \\
\hline 35-39 años & 130,305 & 62,230 & 68,075 & 69.84 & 47.76 & 52.24 \\
\hline 40-44 años & 129,576 & 65,355 & 64,221 & 77.73 & 50.44 & 49.56 \\
\hline 45-49 años & 96,960 & 49,392 & 47,568 & 83.64 & 50.94 & 49.06 \\
\hline 50-54 años & 84,952 & 43,643 & 41,309 & 88.81 & 51.37 & 48.63 \\
\hline 55-59 años & 59,830 & 28,894 & 30,936 & 92.46 & 48.29 & 51.71 \\
\hline 60-64 años & 45,543 & 21,247 & 24,296 & 95.23 & 46.65 & 53.35 \\
\hline 65-69 años & 30,437 & 13,646 & 16,791 & 97.08 & 44.83 & 55.17 \\
\hline 70-74 años & 19,971 & 9,635 & 10,336 & 98.30 & 48.24 & 51.76 \\
\hline 75 años y más & 26,710 & 11,991 & 14,719 & 99.93 & 44.89 & 55.11 \\
\hline No especificado & 1,188 & 625 & 563 & & & \\
\hline
\end{tabular}

Notas: * Porcentaje acumulado. ** Porcentaje respecto de su grupo de edad.

Fuente: Encuesta Intercensal 2015 (INEGI, 2015).

Con relación a la pobreza, Tijuana muestra una mejor condición en prácticamente todos los indicadores respecto 
Tijuana ante el confinamiento social impuesto por la covID-19: habitabilidad de las viviendas, entorno urbano y condiciones económicas en los hogares

de los niveles que se registran a escala nacional. Entre las mayores ventajas que tiene el municipio en esta comparación se encuentran el contar con 14.1 puntos porcentuales menos de personas en pobreza, 12 puntos menos en carencia por acceso a servicios básicos en las viviendas y 12.7 puntos menos en la población con un ingreso inferior a la línea de pobreza. En los demás indicadores que presentan mejores posiciones, las distancias se ubican entre 3.6 y 9.5 puntos porcentuales. En este escenario sorprende que el único indicador que muestra una desventaja para Tijuana sea la carencia en el acceso a servicios de salud, la cual alcanza una diferencia de 5.5 puntos de más respecto a la que se registra a escala nacional (21 contra 15.5\%).

Cuadro 3. Medición de la pobreza en Tijuana y a escala nacional, 2015. Porcentajes por indicador de pobreza

\begin{tabular}{ccc}
\hline Indicadores & Tijuana & Nacional $^{*}$ \\
\hline Pobreza & & \\
\hline Población en situación de pobreza & 29.5 & 43.6 \\
Población en situación de pobreza moderada & 27.6 & 35.9 \\
Población en situación de pobreza extrema & 1.8 & 7.6 \\
Indicadores de carencia social & & \\
$\quad$ Rezago educativo & 12.7 & 17.4 \\
Carencia por acceso a los servicios de salud & 21.0 & 15.5 \\
$\quad$ Carencia por acceso a la seguridad social & 46.3 & 55.8 \\
Carencia por calidad y espacios de la vivienda & 8.4 & 12.0 \\
Carencia por acceso a los servicios básicos en la & 7.3 & 19.3 \\
$\quad$ vivienda & & \\
$\quad$ Carencia por acceso a la alimentación & 13.9 & 20.1 \\
\hline$\quad$ Bienestar & & \\
\hline Población con ingreso inferior a la línea de & 9.5 & 17.5 \\
$\quad$ pobreza extrema por ingresos & & \\
Población con ingreso inferior a la línea de & 37.9 & 50.6 \\
$\quad$ pobreza por ingresos & & \\
\hline
\end{tabular}

*Los datos nacionales corresponden a 2016 debido a que no se generaron mediciones para ese nivel en 2015.

Fuentes: Para Tijuana coneval (2015), y a escala nacional coneval (2017). 
El hecho de que la cobertura de los servicios de salud en Tijuana sea menor que a escala nacional se explica principalmente por la baja afiliación al extinto Seguro Popular, ya que en las demás instituciones la cobertura es mayor o ligeramente inferior (véase cuadro 4). Otro dato que resulta particularmente sobresaliente es la alta cobertura del IMSS en la ciudad, que se encuentra más de veinte puntos porcentuales por encima del promedio nacional.

Cuadro 4. Distribución porcentual de la población según condición de afiliación a servicios de salud e institución a nivel nacional y en

Tijuana, 2015

\begin{tabular}{|c|c|c|c|c|c|c|c|c|c|}
\hline \multirow[b]{3}{*}{ Nivel } & \multicolumn{9}{|c|}{ Condición de afiliación a servicios de salud ${ }^{1}$} \\
\hline & \multicolumn{7}{|c|}{ Afiliada ${ }^{2}$} & \multirow[b]{2}{*}{ 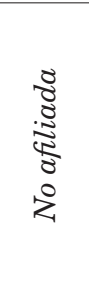 } & \multirow[b]{2}{*}{$\begin{array}{l}\text { 过 } \\
\text { 之 }\end{array}$} \\
\hline & $\underset{\mathbb{z}}{\overrightarrow{0}}$ & $\begin{array}{l}\text { के } \\
\text { है }\end{array}$ & 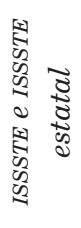 & 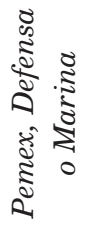 & 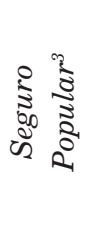 & 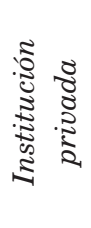 & 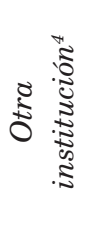 & & \\
\hline Nacional & 82.18 & 39.18 & 7.71 & 1.15 & 49.90 & 3.27 & 1.55 & 17.25 & 0.57 \\
\hline Tijuana & 78.44 & 61.52 & 6.20 & 0.34 & 26.75 & 5.72 & 1.88 & 21.20 & 0.36 \\
\hline
\end{tabular}

1. La distribución porcentual de la condición de afiliación a servicios de salud se calcula respecto de la población total. 2. El porcentaje para cada institución de servicios de salud se obtuvo con respecto a la población afiliada. La suma de los porcentajes puede ser mayor a 100\%, debido a las personas que están afiliadas en más de una institución de salud. 3. Incluye al Sistema de Protección Social en Salud (SPSS) que coordina la Secretaría de Salud (SSA). 4. Incluye otras instituciones de salud públicas y privadas del país. 5. No especificado.

Fuente: Encuesta Intercensal 2015 (INEGI, 2015).

La ventaja que representa contar con una cobertura del IMSS muy superior y considerando además los derechohabientes del ISSSTE, podría hacernos suponer que Tijuana estaría mejor preparada para afrontar un riesgo sanitario como el que representa la pandemia de la Covid; sin

\section{6}


Tijuana ante el confinamiento social impuesto por la covID-19: habitabilidad de las viviendas, entorno urbano y condiciones económicas en los hogares

embargo, como puede apreciarse en el cuadro 5, esa mayor cobertura de la seguridad social no se corresponde con una mayor disponibilidad de infraestructura hospitalaria, la cual está muy por debajo de ciudades como Monterrey, Guadalajara, Puebla y León en lo que corresponde a consultorios y camas de hospital.

Cuadro 5. Indicadores de infraestructura hospitalaria pública y privada en algunos de los municipios más poblados de México

\begin{tabular}{|c|c|c|}
\hline $\begin{array}{c}\text { Municipio o } \\
\text { alcaldía }\end{array}$ & $\begin{array}{c}\text { Densidad de consultorios } \\
\text { de hospitales por cada } 10 \\
\text { mil habitantes }\end{array}$ & $\begin{array}{l}\text { Densidad de camas } \\
\text { hospitalarias por cada } \\
10 \text { mil habitantes }\end{array}$ \\
\hline Monterrey & 11.50 & 43.60 \\
\hline Guadalajara & 8.21 & 36.40 \\
\hline Puebla & 4.58 & 21.50 \\
\hline León & 6.30 & 15.30 \\
\hline Juárez & 2.92 & 12.30 \\
\hline Tijuana & 3.00 & 11.80 \\
\hline Iztapalapa & 2.58 & 9.27 \\
\hline Zapopan & 2.17 & 9.19 \\
\hline Ecatepec de Morelos & 2.31 & 6.90 \\
\hline
\end{tabular}

Fuente: Elaboración propia con datos del Visualizador analítico para la covid-19 [Descarga de datos y metadatos INEGI. Indicadores], en INEGI (2020).

En lo que respecta a las viviendas, al igual que los indicadores de carencias de CONEVAL relacionados, los datos que arroja la Encuesta Intercensal 2015 también nos permiten suponer, en una primera apreciación, que los habitantes de Tijuana cuentan con viviendas apropiadas para afrontar los efectos del "Quédate en casa". En particular, los indicadores de hacinamiento, disponibilidad de servicios básicos y calidad constructiva nos muestran que las edificaciones tienen los espacios adecuados y que en casi la totalidad cuentan con agua, drenaje y electricidad, y los pisos, techos y paredes están construidos con materiales de buena calidad. 
No obstante, debemos señalar que algunos indicadores no reflejan las desigualdades en las condiciones habitacionales en una ciudad; particularmente en el caso de Tijuana, el índice agregado de hacinamiento no da cuenta de que en 2015 el $22.85 \%$ de las viviendas presentó algún grado de hacinamiento; es decir, que en un cuarto duermen más de dos personas (CONAPO, 2016, pp. 14 y 75). Por otra parte, cuando asociamos el equipamiento y los bienes disponibles en las viviendas con las actividades que implica el confinamiento, encontramos que en alrededor de la mitad de los casos no se podrían llevar a cabo actividades laborales y educativas que requieran el uso de Internet y una computadora, y que en casi el $43 \%$ el esparcimiento mediante el uso de la televisión tendría que ceñirse a la programación abierta. Por otra parte, aun considerando que casi el 65\% de las viviendas cuenta con focos ahorradores, lo más probable es que el consumo de electricidad se vea incrementado en todos los hogares, así como el de agua y de telefonía celular.

Cuadro 6. Viviendas particulares habitadas en Tijuana y diversos indicadores de tipo de tenencia y condiciones de habitabilidad, 2015

\begin{tabular}{cc}
\hline Indicador & Valor \\
\hline Total de viviendas particulares habitadas & 475,341 \\
Promedio de ocupantes en viviendas particulares habitadas & 3.45 \\
Promedio de ocupantes por cuarto (índice de hacinamiento) & 0.93 \\
Porcentaje de viviendas con agua entubada & 98.12 \\
Porcentaje de viviendas con electricidad & 99.63 \\
Porcentaje de viviendas con drenaje & 98.28 \\
Porcentaje de viviendas que disponen de sanitario & 99.47 \\
Porcentaje de viviendas particulares habitadas propias & 55.73 \\
Porcentaje de viviendas particulares habitadas alquiladas & 29.59 \\
Porcentaje de viviendas particulares habitadas de un familiar & 13.11 \\
o prestada & 0.27 \\
Porcentaje de viviendas particulares habitadas con tenencia & \\
\hline
\end{tabular}

\section{8}


Tijuana ante el confinamiento social impuesto por la covID-19: habitabilidad de las viviendas, entorno urbano y condiciones económicas en los hogares

\begin{tabular}{|c|c|}
\hline Indicador & Valor \\
\hline $\begin{array}{l}\text { Porcentaje de viviendas particulares habitadas en otra } \\
\text { situación de tenencia }\end{array}$ & 1.31 \\
\hline Porcentaje de viviendas con piso de tierra & 1.41 \\
\hline $\begin{array}{l}\text { Porcentaje de viviendas particulares habitadas con techos } \\
\text { precarios }\end{array}$ & 0.45 \\
\hline $\begin{array}{l}\text { Porcentaje de viviendas particulares habitadas con paredes } \\
\text { precarias }\end{array}$ & 0.71 \\
\hline $\begin{array}{l}\text { Porcentaje de viviendas particulares habitadas que disponen } \\
\text { de Internet }\end{array}$ & 51.29 \\
\hline $\begin{array}{l}\text { Porcentaje de viviendas particulares habitadas que disponen } \\
\text { de computadora }\end{array}$ & 48.84 \\
\hline $\begin{array}{l}\text { Porcentaje de viviendas particulares habitadas que disponen } \\
\text { de teléfono celular }\end{array}$ & 91.14 \\
\hline $\begin{array}{l}\text { Porcentaje de viviendas particulares habitadas que disponen } \\
\text { de teléfono fijo }\end{array}$ & 41.58 \\
\hline $\begin{array}{l}\text { Porcentaje de viviendas particulares habitadas que disponen } \\
\text { de televisión de paga }\end{array}$ & 57.39 \\
\hline $\begin{array}{c}\text { Porcentaje de viviendas donde todos sus focos son } \\
\text { ahorradores }\end{array}$ & 64.80 \\
\hline $\begin{array}{c}\text { Porcentaje de viviendas que disponen de calentador solar de } \\
\text { agua }\end{array}$ & 4.03 \\
\hline $\begin{array}{c}\text { Porcentaje de viviendas que disponen de panel solar para } \\
\text { tener electricidad }\end{array}$ & 0.58 \\
\hline
\end{tabular}

Fuente: Encuesta intercensal 2015 (INEGI, 2015).

Además del hacinamiento que afecta a casi una cuarta parte de la viviendas, de las dificultades para desarrollar ciertas actividades en ellas y del incremento de los gastos por aumento en los consumos de diversos servicios, hay que considerar que la vulnerabilidad de la población ante la pandemia puede distribuirse de manera inequitativa en la ciudad, y los potenciales riesgos aumentan en función de otros indicadores, además de los de vivienda, asociados con características de la población y la densidad poblacional. En el estudio que construyó un índice de vulnerabilidad social ante la covid para Baja California, que consideró tres dimensiones de análisis (véase nota al pie de página 2), se encontró 
que en el caso de Tijuana poco más del $55 \%$ de la población reside en AGEB con vulnerabilidad medio alta (42.9\%) y alta (12.4\%) (Sánchez, Morales y Lares, 2020a, p. 11).

Como se comentó en las consideraciones teórico-metodológicas, otro aspecto que hay que tomar en cuenta para completar el panorama de la situación de la ciudad, frente a la pandemia y al confinamiento, es la calidad del entorno urbano adyacente a las viviendas, ya que la presencia o ausencia de los elementos que lo conforman dará a la población una mayor o menor calidad de vida ante el aislamiento, como una menor contaminación por la presencia de pavimento o de áreas arboladas o una mayor seguridad por la existencia de alumbrado. La calidad del entorno también podría afectar la posibilidad de realizar algún tipo de actividad al aire libre, como caminar o hacer ejercicio, manteniendo la "sana distancia".

Cuadro 7. Niveles de cobertura en las manzanas* según el porcentaje de sus vialidades con los principales elementos que conforman el entorno urbano en Tijuana, 2014

\begin{tabular}{|c|c|c|c|c|c|}
\hline $\begin{array}{l}\text { Niveles de cobertura } \\
\text { en las vialidades }\end{array}$ & 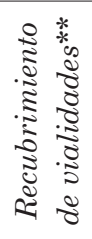 & 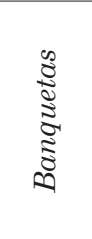 & 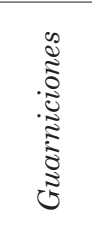 & 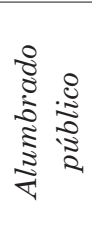 & 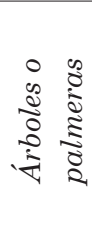 \\
\hline $0 \%$ & 12.5 & 24.8 & 16.9 & 6.0 & 25.2 \\
\hline Entre 1 y $25 \%$ & 6.1 & 7.6 & 7.5 & 4.6 & 12.5 \\
\hline Entre 25.1 y $50 \%$ & 10.6 & 10.9 & 12.4 & 12.5 & 18.3 \\
\hline Entre 50.1 y $75 \%$ & 18.9 & 16.3 & 18.9 & 23.4 & 17.5 \\
\hline Más del $75.1 \% * * *$ & 51.9 & 40.4 & 44.3 & 53.5 & 26.4 \\
\hline Total & 100.0 & 100.0 & 100.0 & 100.0 & 100.0 \\
\hline
\end{tabular}

* El total de manzanas que conforman el municipio es de 21,899, pero hay un $2 \%$ (439 manzanas) que no tiene una especificación, por lo que fueron excluidas de este análisis. ** Incluye pavimento, cemento, adoquín y empedrado. *** Incluye un $8 \%$ de manzanas que fueron catalogadas como conjuntos habitacionales. 
Tijuana ante el confinamiento social impuesto por la coviD- 19: habitabilidad de las viviendas, entorno urbano y condiciones económicas en los hogares

Fuente: Elaboración propia con información de la base de datos denominada "Características de las localidades y del entorno urbano 2014" (INEGI, 2014).

De acuerdo con la base de datos denominada "Características de las localidades y del entorno urbano 2014" (INEGI, 2014), de las 21,460 manzanas que conforman el municipio de Tijuana hay entre un $6 \%$ y un $25 \%$ que no cuenta en ninguna de sus vialidades con alguno de los elementos que determinan un entorno urbano adecuado; los mayores déficits que presentan estas manzanas en sus vialidades son la falta de árboles y banquetas (con alrededor del 25\%), seguida de guarniciones (16.9\%) y recubrimientos (12.5\%), y en menor medida de alumbrado público (6\%). En el extremo superior encontramos que en alrededor de la mitad de las manzanas casi la totalidad o la totalidad de sus vialidades cuentan con recubrimientos y alumbrado, entre $40 \%$ y $45 \%$ con banquetas y guarniciones, y en un poco más del $26 \%$ con árboles o palmeras. Si consideramos solo las manzanas que cuentan con los cinco elementos analizados, descubrimos que apenas el $14.4 \%$ de las manzanas en Tijuana cuenta con un entorno urbano consolidado y, en contra parte, más del $85 \%$ presenta algún déficit en este ámbito del desarrollo urbano.

\section{La CovID 19 en Tijuana: un análisis de los datos al I I} de julio de 2020 (18:18 horas, en horario del Pacífico)

Los datos del impacto de la pandemia en Tijuana presentan un panorama inquietante, por decir lo menos, si lo comparamos con la información que registran los indicadores a escala nacional. Si bien la tasa de contagiados es $25 \%$ menor que el promedio nacional, lo preocupante es que las tasas de mortalidad y de letalidad del virus ${ }^{3}$ en el muni-

3. La tasa de mortalidad mide el número de defunciones por covid por cada 100 mil habitantes, mientras que la tasa de letalidad mide el número de muertes por CoviD por cada 100 personas que fueron confirmadas como contagiadas por el virus. 
cipio son, respectivamente, 1.95 y 2.5 veces mayores que las registradas en el país; en otras palabras, mientras que en el promedio nacional de cada 100 que se enferman por CovID mueren 11.8, en Tijuana fallecen 30.1. ¿Qué podría explicar estas diferencias? En el caso de la baja proporción de confirmados, podría deberse a las diferencias que hay en el indicador de personas estudiadas, considerando que en Tijuana la tasa es $47 \%$ inferior a la registrada en el promedio nacional. Esto podría generar un subregistro de casos confirmados, pero también de negativos, sospechosos y defunciones. ${ }^{4} \mathrm{Si}$ comparamos estos datos con los que se tenían el 2 de junio de 2020; es decir, un mes y nueve días atrás, encontramos que la tasa de confirmados en aquel momento era en Tijuana 56\% superior a la nacional y la tasa de casos estudiados era menor en apenas 16\%. Mientras que a escala nacional el número de casos confirmados se triplicó en este periodo, en Tijuana apenas aumentó en 48\%. Lo mismo pasa con la defunciones: en el país aumentaron 3.2 veces (al pasar de 10,637 a 34,730), y en el municipio apenas $73 \%$ (de 548 a 948$){ }^{5}$

4. En el caso de las defunciones, el estudio de Friedman et al. (2020) encontró que en Tijuana había un exceso de muertes en casa o durante los traslados a una instalación médica, que nunca fueron diagnosticados, ya que no ingresaron a los hospitales, que es de donde surge la mayor parte de las cifras oficiales sobre defunciones por COVID en la ciudad.

5. Los datos al 2 de junio de 2020 sobre covid 19 en Tijuana se informan en Ordóñez (2020). 
Tijuana ante el confinamiento social impuesto por la covID-19: habitabilidad de las viviendas, entorno urbano y condiciones económicas en los hogares

Cuadro 8. Indicadores relacionados con la pandemia ocasionada por el COVID 19 en Tijuana y a nivel nacional, datos al 11 de julio de 2020 (18:18 horas del Pacífico)

\begin{tabular}{ccc}
\hline Indicadores & Nacional & Tijuana \\
\hline Confirmados & 295,268 & 3,150 \\
Negativos & 350,007 & 1,673 \\
Sospechosos & 78,393 & 533 \\
Defunciones & 34,730 & 948 \\
Recuperados & 180,852 & 1,162 \\
Activos & 30,682 & 77 \\
Personas estudiadas* & 723,668 & 5,356 \\
Casos confirmados (\%) & & \\
Mujeres & 45.97 & 42.67 \\
Hombres & 54.03 & 57.33 \\
0-19 años & 3.19 & 1.40 \\
20-39 años & 35.95 & 26.32 \\
40-59 años & 40.90 & 47.37 \\
60-79 años & 17.38 & 21.62 \\
80 y más años & 2.58 & 3.30 \\
Hospitalizados & 29.34 & 60.89 \\
Ambulatorios & 70.66 & 39.11 \\
Hipertensión & 19.95 & 31.97 \\
Diabetes & 16.24 & 26.67 \\
Obesidad & 19.27 & 19.21 \\
Tabaquismo & 7.51 & 7.4 \\
Defunciones: comorbilidades y grupos de edad (\%) & \\
Hipertensión & 42.68 & 45.89 \\
Diabetes & 37.24 & 43.25 \\
Obesidad & 24.93 & 19.83 \\
Tabaquismo & 8.45 & 9.28 \\
0-19 años & 0.36 & 0.63 \\
20-39 años & 6.09 & 8.23 \\
40-59 años & 37.23 & 44.51 \\
60-79 años & 46.44 & 39.24 \\
(años & 9.87 & 7.38 \\
\hline
\end{tabular}




\begin{tabular}{ccc}
\hline Indicadores & Nacional & Tijuana \\
\hline $\begin{array}{c}\text { Tasas de contagios, mortalidad } \\
\text { y letalidad }\end{array}$ & \\
Tasa de personas estudiadas por 100 mil & 566.28 & 299.30 \\
habitantes & & \\
Tasa de confirmados por cada 100 mil & 231.05 & 176.02 \\
habitantes & & \\
Tasa de mortalidad por 100 mil habitantes & 27.18 & 52.97 \\
Tasa de letalidad por cada 100 confirmados & 11.76 & 30.10 \\
Población 2020** & $127,792,286$ & $1,789,531$ \\
\hline
\end{tabular}

* El número de personas estudiadas resulta de la suma del número de confirmados, negativos y sospechosos.

** Las proyecciones de población al 2020 son de CONAPO (2020).

Fuentes: Gobierno de México (2020).

Aun considerando las diferencias en el tiempo, la mortalidad y la letalidad siguen siendo en Tijuana muy elevadas respecto de los promedios nacionales, e incluso son superiores a las del país que registra la mayor tasa de letalidad en el mundo, que es Yemen, con 26.51 muertes por cada 100 confirmados (CISs, 2020, con datos al 9 de julio de 2020). De acuerdo con los especialistas, la edad por encima de los 60 años y las comorbilidades son un factor importante en el desenlace fatal de los contagiados; sin embargo, en el caso de Tijuana las diferencias con los datos nacionales de confirmados y fallecimientos por Covid en lo que se refiere a comorbilidades no son tan grandes para explicar las amplias distancias que hay en las tasas de mortalidad y letalidad del virus. En el caso de las edades, al contrario de lo que se esperaría, en el municipio la proporción de muertos menores de 60 años es casi 10 puntos porcentuales superior a las cifras nacionales (53.38\% contra 43.69\%, respectivamente).

Algo que también llama la atención del cuadro anterior son las proporciones de los casos confirmados que necesitan hospitalización en Tijuana, respecto de los casos nacionales: $60.9 \%$ contra $29.3 \%$, una diferencia de más de 30 puntos porcentuales. Este dato difiere significativamente 
Tijuana ante el confinamiento social impuesto por la coviD- 19: habitabilidad de las viviendas, entorno urbano y condiciones económicas en los hogares

de las cifras presentadas por la Secretaría de Salud de Baja California, cuyo titular afirmó en su conferencia del 13 de julio de 2020 que en Tijuana los casos confirmados que requirieron hospitalización era de apenas el 3.7\%. En esta misma conferencia se informó que los dos hospitales que fueron reconvertidos para la atención de pacientes con COvid en la ciudad (el Hospital General, a cargo de la Secretaría de Salud, y el Hospital General Regional 1, del IMss) y el hospital de apoyo (el Hospital General Regional 20 del IMSS) contaban al 12 de julio de 422 camas para covid y 128 ventiladores, de los cuales estaban disponibles ese día 267 camas y 59 ventiladores, con una ocupación hospitalaria de camas para Covid del $36.7 \%$ y una disponibilidad de ventiladores del 46.1\% (Pérez, 2020).

4. Análisis de los resultados del cuestionario según las dimensiones de habitabilidad de las viviendas, el entorno urbano y las condiciones económicas de las familias

a) La habitabilidad de las viviendas

Como se comentó en el primer apartado, el estudio tradicional de la habitabilidad pasa por un conjunto de temas que aluden a las cualidades de las viviendas para proveer bienestar, seguridad y protección física, de la vida y la salud de sus residentes (onu-Hábitat, 2018). En condiciones de confinamiento, habría que agregar a estos beneficios la capacidad de las viviendas para ofrecer a sus ocupantes la posibilidad de realizar actividades que normalmente no se realizan en casa, como llevar un programa de estudios, trabajar o ejercitarse.

De esta manera, para acatar la medida de "Quédate en casa" manteniendo cierta calidad de vida, es indispensable contar con una vivienda con condiciones de habitabilidad adecuadas para los diferentes tipos de hogares, según el número de miembros, edades, tipo de actividades que 
desarrollan (laborales, educativas, lúdicas, de cuidado o domésticas), así como en lo referente a las dimensiones (metros cuadrados) y la calidad constructiva de las viviendas, número de cuartos y baños, disponibilidad de servicios básicos (agua y drenaje), acceso a teléfono de línea e Internet, teléfonos celulares y computadoras.

Partiendo de estos planteamientos, enseguida se expondrán los resultados del cuestionario respecto de las características de las viviendas contenidas en la muestra, de sus residentes y de sus condiciones de habitabilidad, así como de las actividades que se llevan a cabo en las viviendas a partir del "Quédate en casa", y los principales problemas que ha representado a los hogares esta medida.

\section{Las viviendas y sus residentes}

De acuerdo con los tipos de vivienda, los resultados del cuestionario indican que el que más predomina son las casas (83\%), principalmente en fraccionamientos o conjuntos habitacionales $(42.8 \%)$, pero también las hay en colonias consolidadas (26.6\%) o en colonias populares (13.7\%); en contraste, los departamentos apenas representan el $17 \%$ de las viviendas, sea en condominios (10\%), en unidades habitacionales $(5.2 \%)$ o en vecindades $(1.8 \%)$. Desde el punto de vista de la tenencia, casi tres cuartas partes de las viviendas son propias, pero dentro de estas alrededor del $37 \%$ aún se está pagando; por otra parte, el $22.5 \%$ es de rentadas y el restante $4.4 \%$ es prestado o se encuentra en otra situación.

Según sus dimensiones y espacios disponibles, las viviendas cuentan en promedio con una superficie de $215 \mathrm{~m}^{2}, 4.2$ cuartos (incluyendo la cocina) y 2 baños. El promedio de ocupantes por vivienda es de 3.23 personas, y el de ocupantes por cuarto ronda el 0.82 . Por su parte, el $41.4 \%$ dijo que en su vivienda residen niños, niñas y adolescentes, y 
Tijuana ante el confinamiento social impuesto por la covID-19: habitabilidad de las viviendas, entorno urbano y condiciones económicas en los hogares

que en el $23.6 \%$ de los hogares habita al menos un adulto mayor, y la abrumadora mayoría de ellos (más del 82\%) vive acompañada por personas de 60 años o menos.

Con relación a los materiales con que están construidas las viviendas, el $88.2 \%$ respondió de bloque o ladrillo, y solo el $9.5 \%$ de madera u otros materiales. Finalmente, en lo que respecta a la disponibilidad de servicios básicos, los resultados del cuestionario indican que casi en su totalidad las viviendas cuentan con agua conectada a la red pública (99.6\%), y que la reciben todos los días (93.7\%), que disponen de drenaje (94.5\%) y con servicio de recolección de basura (92.6\%), pero en alrededor de la mitad de los casos se registró la inexistencia del servicio de seguridad pública.

Cuadro 9. Indicadores básicos de la habitabilidad de las viviendas

\begin{tabular}{|c|c|c|c|c|c|c|}
\hline \multirow[b]{2}{*}{ Indicadores } & \multicolumn{2}{|c|}{ Tipo de colonias } & \multicolumn{3}{|c|}{ Tipo de viviendas } & \multirow[b]{2}{*}{ 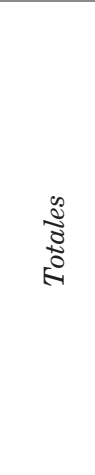 } \\
\hline & 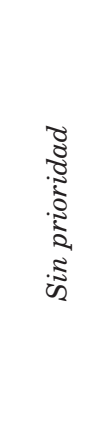 & 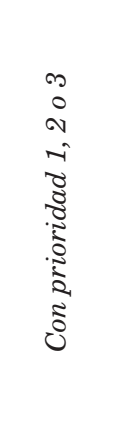 & 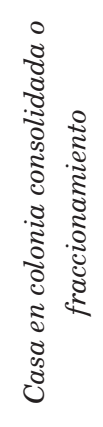 & 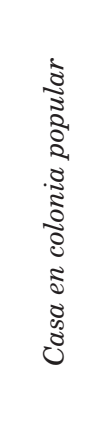 & 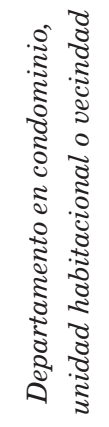 & \\
\hline $\begin{array}{l}\text { Promedio de habitantes } \\
\text { en las viviendas }\end{array}$ & 3.13 & 3.53 & 3.20 & 3.89 & 2.74 & 3.23 \\
\hline $\begin{array}{l}\text { Promedio de } \mathrm{m}^{2} \text { de } \\
\text { superficie de las } \\
\text { viviendas }\end{array}$ & 242.43 & 124.06 & 253.53 & 112.23 & 129.03 & 214.17 \\
\hline $\begin{array}{c}\text { Promedio de } \mathrm{m}^{2} \\
\text { de superficie de la } \\
\text { vivienda por residente }\end{array}$ & 90.97 & 45.51 & 97.17 & 31.54 & 52.43 & 79.90 \\
\hline $\begin{array}{l}\text { Promedio de cuartos en } \\
\text { la vivienda (incluida la } \\
\text { cocina) }\end{array}$ & 4.21 & 4.08 & 4.29 & 4.32 & 3.61 & 4.18 \\
\hline
\end{tabular}




\begin{tabular}{|c|c|c|c|c|c|c|}
\hline \multirow[b]{2}{*}{ Indicadores } & \multicolumn{2}{|c|}{ Tipo de colonias } & \multicolumn{3}{|c|}{ Tipo de viviendas } & \multirow[b]{2}{*}{ 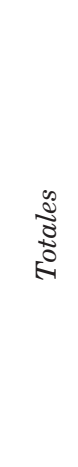 } \\
\hline & 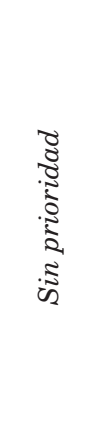 & 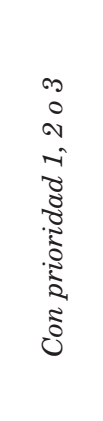 & 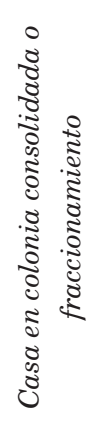 & 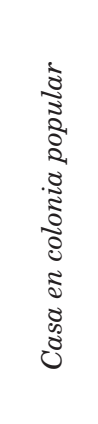 & 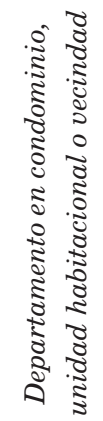 & \\
\hline $\begin{array}{l}\text { Promedio de personas } \\
\text { por cuarto }\end{array}$ & 0.76 & 1.00 & 0.79 & 0.93 & 0.84 & 0.82 \\
\hline $\begin{array}{c}\text { Promedio de baños en } \\
\text { las viviendas }\end{array}$ & 2.06 & 1.63 & 2.18 & 1.59 & 1.37 & 1.96 \\
\hline $\begin{array}{l}\text { Porcentaje de hogares } \\
\text { con niños, niñas o } \\
\text { adolescentes }\end{array}$ & 39.50 & 50.00 & 43.80 & 44.40 & 28.20 & 41.40 \\
\hline $\begin{array}{l}\text { Porcentaje de hogares } \\
\text { con adultos mayores }\end{array}$ & 24.00 & 23.40 & 23.50 & 30.60 & 17.90 & 23.60 \\
\hline $\begin{array}{c}\text { Porcentaje de viviendas } \\
\text { construidas con bloque } \\
\text { o ladrillo }\end{array}$ & 89.40 & 84.40 & 92.60 & 56.80 & 95.70 & 88.20 \\
\hline $\begin{array}{l}\text { Porcentaje de viviendas } \\
\text { con agua conectada a la } \\
\text { red púbica }\end{array}$ & 99.50 & 100.00 & 99.50 & 100.00 & 100.00 & 99.60 \\
\hline $\begin{array}{l}\text { Porcentaje de viviendas } \\
\text { que cuenta con agua } \\
\text { de la red pública todos } \\
\text { los días }\end{array}$ & 94.20 & 92.20 & 94.70 & 91.90 & 91.30 & 93.70 \\
\hline $\begin{array}{l}\text { Porcentaje de viviendas } \\
\text { con drenaje }\end{array}$ & 93.20 & 98.40 & 96.30 & 89.20 & 91.30 & 94.50 \\
\hline $\begin{array}{l}\text { Porcentaje de viviendas } \\
\text { con servicio de } \\
\text { recolección de basura }\end{array}$ & 93.20 & 90.60 & 94.10 & 89.20 & 89.10 & 92.60 \\
\hline $\begin{array}{l}\text { Porcentaje de viviendas } \\
\text { con servicio de } \\
\text { seguridad pública }\end{array}$ & 51.20 & 42.20 & 59.60 & 8.10 & 39.10 & 49.10 \\
\hline
\end{tabular}

Fuente: Elaboración propia con información de UNAM-IIS (2020) y Sánchez, Morales y Lares (2020b). 
Tijuana ante el confinamiento social impuesto por la coviD- 19: habitabilidad de las viviendas, entorno urbano y condiciones económicas en los hogares

Cuando se revisan estos indicadores según los tipos de colonias o de viviendas, hay algunos que muestran diferencias importantes, particularmente en los promedios de residentes, de metros cuadrados de superficie de las viviendas y por residente, y de baños, así como en los porcentajes de hogares con niños, niñas o adolescentes (NNA) y con adultos mayores (AM). En todos estos casos, se advierten desventajas en las viviendas en colonias identificadas con algún nivel de prioridad, en las casas en colonias populares y en todo tipo de departamentos. Según los miembros de los hogares, no resulta sorprendente que en las colonias prioritarias y en las casas en colonias populares haya un promedio mayor que en los otros tipos, así como mayores porcentajes de hogares con NNA (prioritarias) y de AM (populares); en contraste, en los departamentos hay menos miembros y menores porcentajes de hogares con NNA y AM. Tampoco es extraordinario que en estos tipos de colonias y viviendas se cuente con menores superficies, cuartos y baños, y que en las colonias populares haya un porcentaje mucho menor de viviendas construidas con materiales durables. Lo que sí resulta un poco fuera de lo esperado es que las casas en las colonias populares tengan superficies de menor tamaño que los departamentos, lo cual impacta en una mucha menor disponibilidad de metros cuadrados por residente, ya que también viven en ellas un número mayor de personas. En lo que respecta a los servicios las diferencias no son tan marcadas, con excepción de la seguridad pública, que es menor en las colonias prioritarias y en los departamentos y mucho menor en las casas en colonias populares.

Aun considerando las diferencias comentadas en el párrafo anterior, es posible afirmar que incluso en las viviendas que presentan desventajas los parámetros básicos están dentro de los rangos aceptables de habitabilidad para las condiciones de vida normales de una familia y, en alguna medida, para la coyuntura que representan la pandemia 
y sus implicaciones en cuanto a la atención de algunas de las recomendaciones al respecto, como lo serían disponer de agua para lavarse las manos, y de servicios que proporcionan un saneamiento indispensable, como el drenaje y la recolección de basura. Este escenario no se cumple a cabalidad en el $43 \%$ de las casas ubicadas en colonias populares, considerando que la calidad constructiva de las viviendas no es la adecuada. En el marco del confinamiento, los hogares que muy probablemente enfrenten mayores problemas sean los que residen en las colonias prioritarias y en casas en colonias populares, tomando en cuenta los altos porcentajes de hogares con NNA y AM, respectivamente, cuyos cuidados y atención demandan tiempo y mejores condiciones. Pero veamos enseguida con más detalle algunos otros aspectos de la habitabilidad que requieren las viviendas ante el confinamiento.

\section{Otros elementos de la habitabilidad de las viviendas} y actividades y problemáticas ante el confinamiento

Otros elementos de la vivienda que proporcionan mejores condiciones de habitabilidad se relacionan con contar con ventilación o con espacios que permitan hacer actividades al aire libre sin salir de casa o en el interior de los edificios o unidades habitacionales en el caso de los departamentos. En el cuadro 10 se muestran los resultados para algunos elementos o espacios de este tipo; como se puede apreciar, la totalidad de las viviendas de nuestra muestra cuenta con ventanas y casi un $85 \%$ con patio, aunque solo un poco más de la mitad tiene jardín o áreas verdes, un tercio balcón y menos del 16\% dispone de aire acondicionado.

$\mathrm{Al}$ analizar estos elementos según los tipos de colonias y de viviendas, observamos que las viviendas en colonias con algún nivel de prioridad, aunque tienen una proporción más alta de patios respecto de las no prioritarias, su 
Tijuana ante el confinamiento social impuesto por la covID-19: habitabilidad de las viviendas, entorno urbano y condiciones económicas en los hogares

disponibilidad de jardines o áreas verdes y de aires acondicionados es menor. En lo que respecta a los diferentes tipos de viviendas, hay una tendencia clara a la reducción de las viviendas que cuentan con patios o jardines al pasar de las casas en colonias consolidadas o en fraccionamientos a casas en colonias populares, y de estas a departamentos. En el caso de los balcones y aires acondicionados, la tendencia se rompe a favor de los departamentos respecto de las casas en colonias populares, muy claramente en el primer caso y ligeramente en el segundo.

Cuadro 10. Espacios u otros elementos disponibles en las viviendas $(\%)$

\begin{tabular}{|c|c|c|c|c|c|c|}
\hline \multirow[b]{2}{*}{ Indicador } & \multicolumn{2}{|c|}{ Tipo de colonias } & \multicolumn{3}{|c|}{ Tipo de viviendas } & \multirow[b]{2}{*}{ Totales } \\
\hline & 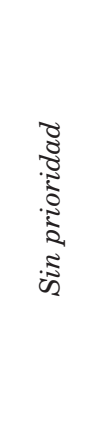 & 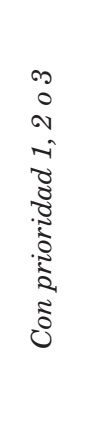 & 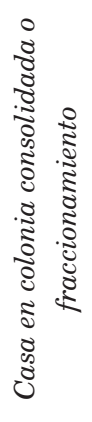 & 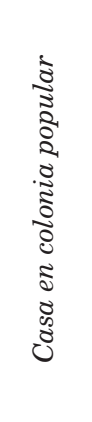 & 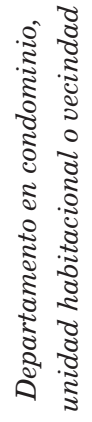 & \\
\hline Ventanas & 100.0 & 100.0 & 100.0 & 100.0 & 100.0 & 100.0 \\
\hline Patio & 82.6 & 90.6 & 94.1 & 86.5 & 43.5 & 84.5 \\
\hline Escaleras & 84.1 & 70.3 & 88.3 & 64.9 & 63.0 & 80.8 \\
\hline $\begin{array}{c}\text { Jardín o áreas } \\
\text { verdes }\end{array}$ & 54.6 & 40.6 & 55.3 & 45.9 & 39.1 & 51.3 \\
\hline Balcón & 37.2 & 18.8 & 33.5 & 16.2 & 43.5 & 32.8 \\
\hline Aire acondicionado & 17.9 & 9.4 & 18.6 & 8.1 & 10.9 & 15.9 \\
\hline
\end{tabular}

Fuente: Elaboración propia con información de UNAM-IIS (2020) y Sánchez, Morales y Lares (2020b). 
Actividades que se realizan en la vivienda desde el "Quédate en casa" y principales problemas de las familias ante el confinamiento

El confinamiento ha incrementado la cantidad y la intensidad en la realización de algunas actividades en casa y, como se puede observar en la tabla siguiente predominan las tareas domésticas y las actividades laborales en línea y de esparcimiento a través de los sistemas de cable; las actividades que menos se realizan son las que requieren hacer ejercicio y aprender en casa, las cuales se llevan a cabo en menos de la mitad de las viviendas. Aunque se mantienen las tres actividades principales en todos los tipos de colonias y viviendas, en la colonias prioritarias y populares se presenta una sensible baja en lo que se refiere al trabajo en línea y a ver contenidos a través de sistemas de paga; lo mismo sucede para el resto de las actividades, con excepción de ver televisión, en las casas en colonias populares. Muy probablemente influya en estas tendencias un menor acceso a Internet e ingresos insuficientes para sufragar los costos que implican la conectividad y los sistemas de televisión por cable. 
Tijuana ante el confinamiento social impuesto por la covID-19: habitabilidad de las viviendas, entorno urbano y condiciones económicas en los hogares

Cuadro 10. Actividades en las viviendas desde el "Quédate en casa"

(\%)

\begin{tabular}{|c|c|c|c|c|c|c|}
\hline \multirow[b]{2}{*}{ Actividades } & \multicolumn{2}{|c|}{$\begin{array}{l}\text { Tipo de } \\
\text { colonias }\end{array}$} & \multicolumn{3}{|c|}{ Tipo de viviendas } & \multirow[b]{2}{*}{ 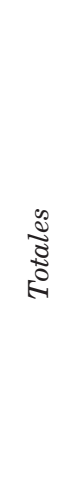 } \\
\hline & 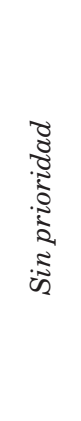 & 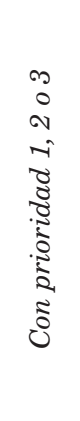 & 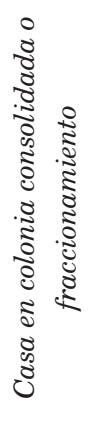 & 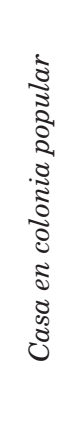 & 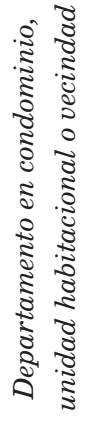 & \\
\hline Tareas domésticas & 91.8 & 92.2 & 93.1 & 89.2 & 89.1 & 91.9 \\
\hline $\begin{array}{c}\text { Ver contenido en Netflix, } \\
\text { Amazon, Claro }\end{array}$ & 81.2 & 68.8 & 85.1 & 51.4 & 71.7 & 78.2 \\
\hline Trabajar en línea & 79.2 & 64.1 & 79.8 & 48.6 & 80.4 & 75.6 \\
\hline $\begin{array}{c}\text { Leer libros, periódicos, } \\
\text { revistas }\end{array}$ & 60.4 & 59.4 & 66.5 & 29.7 & 58.7 & 60.1 \\
\hline $\begin{array}{c}\text { Juegos de mesa y juegos } \\
\text { por Internet }\end{array}$ & 57.5 & 43.8 & 58.0 & 37.8 & 52.2 & 54.2 \\
\hline Hacer gimnasia & 50.7 & 37.5 & 53.2 & 29.7 & 39.1 & 47.6 \\
\hline Aprende en casa & 47.8 & 53.1 & 53.2 & 37.8 & 41.3 & 49.1 \\
\hline Ver televisión & 50.7 & 60.9 & 56.4 & 59.5 & 34.8 & 53.1 \\
\hline
\end{tabular}

Fuente: Elaboración propia con información de UNAM-IIS (2020) y Sánchez, Morales y Lares (2020b).

En lo que se refiere a la distribución de responsabilidades en el hogar, aunque hay la participación de miembros de ambos sexos en muchos de los hogares, en una proporción importante las mujeres siguen siendo las responsables principales de realizarlas. En la única actividad en la que se presenta una mayor participación de los hombres es en la compra de alimentos, con un $25.5 \%$ como responsables únicos y un $41.7 \%$ con la responsabilidad compartida con las mujeres. 
Cuadro 11. Distribución de actividades entre sexos ante el confinamiento (\%)

\begin{tabular}{ccccc}
\hline $\begin{array}{c}\text { Quién realiza } \\
\text { la actividad }\end{array}$ & $\begin{array}{c}\text { Trabajo } \\
\text { domestico }\end{array}$ & $\begin{array}{c}\text { Apoyo a } \\
\text { tareas } \\
\text { escolares }\end{array}$ & $\begin{array}{c}\text { Compra de } \\
\text { alimentos }\end{array}$ & $\begin{array}{c}\text { Cuidado de niños, } \\
\text { adultos mayores o } \\
\text { ambos }\end{array}$ \\
\hline Mujeres & 41.7 & 24.4 & 30.3 & 21.0 \\
Hombres & 6.6 & 3.3 & 25.5 & 1.8 \\
Ambos & 48.0 & 15.1 & 41.7 & 16.6 \\
No aplica & 2.6 & 24.4 & 1.5 & 26.6 \\
\hline
\end{tabular}

Fuente: Elaboración propia con información de UNAM-IIS (2020).

En lo que respecta a los problemas de las familias ante el confinamiento, probablemente las buenas condiciones de habitabilidad descritas anteriormente sean la principal razón por la cual las informantes y los informantes consideran que compartir el mismo espacio no sea uno de los principales problemas de mantenerse en casa. Como se aprecia en el cuadro 12 , apenas el 9.6\% lo refirió como un problema. Del mismo modo, no resultan problemas importantes para la mayoría el compartir computadoras, crear condiciones de salubridad, cumplir con la escuela o cuidar mascotas. Los principales problemas que enfrentan las familias tienen que ver con actividades que requieren romper con el confinamiento, incluyendo las actividades laborales que muy probablemente no se puedan llevar a cabo en el contexto de una vivienda. En estos casos, el uso del espacio público, como veremos más adelante, resulta crucial para atender estos problemas.

En la distribución de las problemáticas por tipos de colonia $\mathrm{y}$ vivienda el orden de mayor a menor frecuencia se mantiene en todos los casos, pero la intensidad varía en algunos tipos. Particularmente las problemáticas relacionadas con la provisión de alimentos y la realización de actividades laborales se intensifican en las viviendas ubicadas en colonias prioritarias, y en alguna medida las laborales en los departamentos. Por el contrario, en las viviendas en colonias con algún nivel de prioridad el no salir a caminar resulta no ser un problema 
Tijuana ante el confinamiento social impuesto por la covID-19: habitabilidad de las viviendas, entorno urbano y condiciones económicas en los hogares

para la mayoría y también para quienes habitan en departamentos, aunque en menor medida. Lo que sí es un tanto sorprendente es que el cumplir con la escuela en casa no sea un problema relevante para más del $80 \%$ de las familias, aun cuando el porcentaje de hogares con miembros que estudian es alto en todos los casos.

Cuadro 12. Principales problemas de las familias para cumplir con el "Quédate en casa" (\%)

\begin{tabular}{|c|c|c|c|c|c|c|}
\hline \multirow[b]{2}{*}{ Indicador } & \multicolumn{2}{|c|}{ Tipo de colonias } & \multicolumn{3}{|c|}{ Tipo de viviendas } & \multirow[b]{2}{*}{ 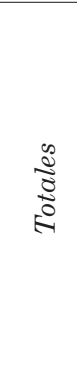 } \\
\hline & 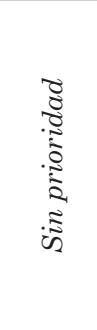 & 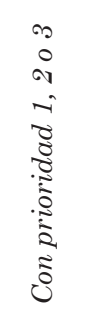 & 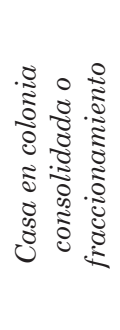 & 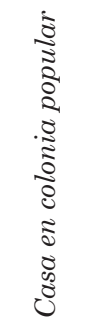 & 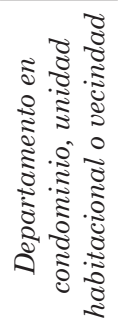 & \\
\hline Proveer de alimentos & 61.8 & 70.3 & 64.4 & 64.9 & 60.9 & 63.8 \\
\hline $\begin{array}{c}\text { Realizar actividad } \\
\text { laboral }\end{array}$ & 42.0 & 54.7 & 43.1 & 45.9 & 52.2 & 45.0 \\
\hline $\begin{array}{l}\text { No salir a caminar y } \\
\text { hacer deporte }\end{array}$ & 51.2 & 23.4 & 46.8 & 40.5 & 39.1 & 44.6 \\
\hline $\begin{array}{l}\text { Cuidado de las } \\
\text { mascotas }\end{array}$ & 13.5 & 14.1 & 14.4 & 10.8 & 13.0 & 13.7 \\
\hline $\begin{array}{c}\text { Cumplir con la escuela } \\
\text { en casa* }^{*}\end{array}$ & 19.2 & 15.5 & 19.4 & 12.5 & 18.5 & 16.6 \\
\hline $\begin{array}{l}\text { Compartir el mismo } \\
\text { espacio }\end{array}$ & 8.7 & 12.5 & 10.1 & 10.8 & 6.5 & 9.6 \\
\hline $\begin{array}{l}\text { Crear condiciones de } \\
\text { salubridad }\end{array}$ & 7.2 & 3.1 & 6.9 & 5.4 & 4.3 & 6.3 \\
\hline $\begin{array}{l}\text { Compartir la(s) } \\
\text { computadora(s) }\end{array}$ & 6.3 & 9.4 & 8.5 & 5.4 & 2.2 & 7.0 \\
\hline $\begin{array}{c}\text { Porcentaje de hogares } \\
\text { con miembros que } \\
\text { estudian }\end{array}$ & 62.80 & 70.30 & 66.00 & 64.90 & 58.70 & 64.60 \\
\hline
\end{tabular}

* Esta variable se calculó considerando solo el subconjunto de viviendas en las que hay al menos un miembro que estudia.

Fuente: Elaboración propia con información de UNAM-IIS (2020) y Sánchez, Morales y Lares (2020b). 
b) Sobre el entorno urbano, el espacio público y la convivencia vecinal

Como se comentó en la segunda sección de este trabajo, Tijuana presenta déficits importantes en algunos componentes del entorno urbano, sobre todo en lo que se refiere a árboles y banquetas, y en menor medida guarniciones, pavimentación y alumbrado público. Los resultados del cuestionario ratifican que la falta de banquetas afecta a casi el 19\% de las viviendas, pero además el 21\% manifestó no contar en las cercanías de sus viviendas con una plaza o parque público, y el $70 \%$ no tener a su alcance un centro cultural o deportivo. Sobre todo esta última limitante convierte a las calles y a las plazas o parques públicos en los únicos espacios en los que la mayoría de los miembros de los hogares disponen para caminar o hacer algún tipo de ejercicio. Esto resulta un asunto de particular importancia, dado que para buena parte de los hogares el no poder llevar a cabo estas actividades se considera como uno sus principales problemas, y que seguramente persistirá más allá del fin del confinamiento a que obliga el "quédate en casa". La problemática de los déficits en el entorno urbano se agudiza en las casas en colonias populares para los tres elementos considerados, y en las viviendas con colonias prioritarias la escasa disponibilidad de centros culturales o deportivos. 
Tijuana ante el confinamiento social impuesto por la covID-19: habitabilidad de las viviendas, entorno urbano y condiciones económicas en los hogares

Cuadro 13. Características del entorno urbano y del espacio público (\%)

\begin{tabular}{|c|c|c|c|c|c|c|}
\hline \multirow[b]{2}{*}{$\begin{array}{c}\text { Cerca de su } \\
\text { vivienda hay... }\end{array}$} & \multicolumn{2}{|c|}{ Tipo de colonias } & \multicolumn{3}{|c|}{ Tipo de viviendas } & \multirow[b]{2}{*}{ Totales } \\
\hline & 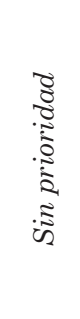 & 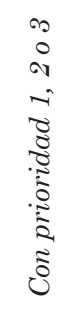 & 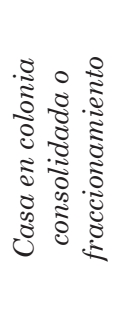 & 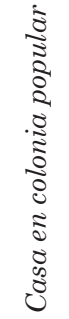 & 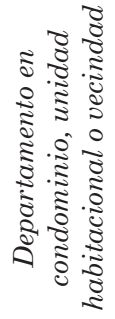 & \\
\hline Banquetas & 81.6 & 79.7 & 84.6 & 64.9 & 80.4 & 81.9 \\
\hline Plaza o parque & 78.3 & 81.3 & 80.9 & 67.6 & 80.4 & 79.0 \\
\hline $\begin{array}{l}\text { Centro cultural } \\
\text { o deportivo }\end{array}$ & 31.4 & 23.4 & 31.9 & 8.1 & 37.0 & 29.5 \\
\hline $\begin{array}{l}\text { Mercado } \\
\text { público }\end{array}$ & 38.2 & 45.3 & 40.4 & 40.5 & 37.0 & 39.9 \\
\hline $\begin{array}{l}\text { Tienda de } \\
\text { abarrotes }\end{array}$ & 72.9 & 87.5 & 73.9 & 89.2 & 76.1 & 76.4 \\
\hline Oxxo u otro & 93.2 & 95.3 & 95.2 & 83.8 & 95.7 & 93.7 \\
\hline Supermercado & 82.6 & 73.4 & 85.1 & 62.2 & 76.1 & 80.4 \\
\hline $\begin{array}{l}\text { Hospital } \\
\text { público }\end{array}$ & 26.1 & 25.0 & 27.7 & 18.9 & 23.9 & 25.8 \\
\hline $\begin{array}{l}\text { Hospital } \\
\text { privado }\end{array}$ & 72.9 & 48.4 & 73.9 & 37.8 & 63.0 & 67.2 \\
\hline Clínica IMSs & 53.1 & 51.6 & 55.3 & 45.9 & 47.8 & 52.8 \\
\hline Clínica Issste & 30.0 & 18.8 & 31.9 & 8.1 & 23.9 & 27.3 \\
\hline Cruz Roja & 19.8 & 21.9 & 21.8 & 10.8 & 21.7 & 20.3 \\
\hline $\begin{array}{c}\text { Centro de salud } \\
\text { y otros }\end{array}$ & 27.1 & 53.1 & 25.5 & 70.3 & 34.8 & 33.2 \\
\hline
\end{tabular}

Fuente: Elaboración propia con información de UNAM-IIS (2020) y Sánchez, Morales y Lares (2020b).

De igual manera, las respuestas del cuestionario mostraron que el proveer alimentos es el principal problema que enfrentan las familias durante el confinamiento, y es en esta actividad donde mayormente participan los hombres, de manera única o compartida con las mujeres. Este problema parece no estar asociado con la cercanía a las viviendas de 
los establecimientos que venden estos productos, ya que en casi el 80\% de los casos manifestó tener cerca un supermercado, en el 94\% un comercio tipo Oxxo y en un $76 \%$ una tienda de abarrotes. Aunque desconocemos el motivo de esta preocupación, podemos suponer que puede deberse a tres factores: al incremento de los costos de los alimentos, a la reducción de los ingresos en los hogares y al temor de contagiarse. Estas problemáticas tenderían a agudizarse en el caso de las colonias populares, considerando que tienen un menor acceso a supermercados, que en teoría cuentan con las mejores condiciones de precio y sanitización que el resto de los establecimientos.

En este supuesto del temor a contagiarse, la cercanía de instalaciones hospitalarias puede ser un factor que contribuya a aliviar la angustia, pero, como podemos observar en el cuadro anterior, la mayor parte de este tipo de establecimientos cercanos a las viviendas de nuestra muestra o son privados o requieren ser derechohabientes para acceder a sus servicios (IMSS e ISSSTE). Solo en menos de una tercera parte de los casos, en sus cercanías cuentan con hospitales públicos, centros de salud o con instalaciones de la Cruz Roja. En las colonias populares y prioritarias la falta de todo tipo de instalaciones hospitalarias es mayor, con excepción de los centros de salud.

Otro de los aspectos de la vida social que se ha visto perturbado por el confinamiento ha sido la convivencia entre los vecinos; como puede apreciarse en el cuadro siguiente, en Tijuana los resultados del cuestionario indican que se continúan realizando en proporciones importantes actividades que están prohibidas (como hacer reuniones sociales) o no están debidamente reguladas o controladas por las autoridades locales (poner música en volumen alto y salir a la calle). En este aspecto, los tres tipos de problemáticas se amplifican en las colonias con algún nivel de prioridad, en las casas en colonias populares y en los departamen- 
Tijuana ante el confinamiento social impuesto por la covID-19: habitabilidad de las viviendas, entorno urbano y condiciones económicas en los hogares

tos. Ante estas conductas, muchas de las propuestas que manifestaron los informantes están orientadas a la aplicación de multas, medidas de control más restrictivas, e incluso la instauración del toque de queda. Al contrario de estas propuestas, pensamos que es una oportunidad para impulsar cambios en la convivencia vecinal por parte de las autoridades locales, principalmente mediante una campaña de concientización que ponga el acento en el respeto y la solidaridad vecinales ante situaciones tan complicadas como las que nos impone la emergencia sanitaria.

Cuadro 14. Actividades que realizan sus vecinos durante el "quédate en casa" (\%)

\begin{tabular}{|c|c|c|c|c|c|c|}
\hline \multirow[b]{2}{*}{ Actividades } & \multicolumn{2}{|c|}{ Tipo de colonias } & \multicolumn{3}{|c|}{ Tipo de viviendas } & \multirow[b]{2}{*}{$\frac{\stackrel{\infty}{0}}{\tilde{\Xi}}$} \\
\hline & 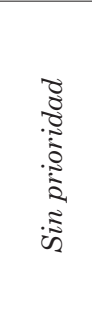 & 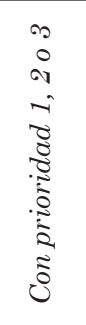 & 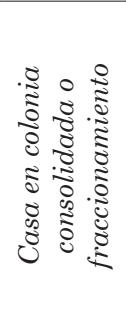 & 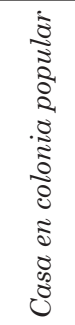 & 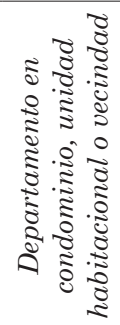 & \\
\hline $\begin{array}{l}\text { Hacen reuniones } \\
\text { sociales }\end{array}$ & 20.8 & 31.3 & 20.7 & 27.0 & 30.4 & 23.2 \\
\hline $\begin{array}{l}\text { Ponen música en } \\
\text { volumen alto }\end{array}$ & 36.2 & 46.9 & 35.6 & 48.6 & 43.5 & 38.7 \\
\hline $\begin{array}{l}\text { Salen frecuentemente } \\
\text { al espacio público o a } \\
\text { la calle }\end{array}$ & 37.2 & 54.7 & 37.2 & 59.5 & 43.5 & 41.3 \\
\hline
\end{tabular}

Fuente: Elaboración propia con información de UNAM-IIS (2020) y Sánchez, Morales y Lares (2020b).

c) Condiciones y problemáticas económicas de las familias ante el confinamiento

En casi la totalidad de las viviendas de la muestra en Tijuana (con excepción del 3\%) hay al menos una persona que trabaja, para un promedio 1.8 trabajadores en estos 
hogares. Según el lugar de trabajo, el grupo de mayor tamaño se desempeña en la empresa privada (48\%), seguido por los que trabajan por cuenta propia (26.6\%), en el gobierno (22.1\%) y en la educación pública (18.8\%); el resto se divide en empresas familiares, organizaciones sociales, trabajadores de la salud o en la educación privada. No obstante, las informantes y los informantes mencionaron que en solo el $87.5 \%$ de las viviendas había algún miembro de la familia que recibía ingresos, es decir, un 10\% menos de viviendas con al menos un trabajador.

Este patrón se repite con diferencias poco significativas entre los distintos subconjuntos de viviendas, con algunas excepciones que merecen una mención aparte: el promedio de trabajadores por hogar es más alto en las casas en colonias populares, pero lo más sobresaliente en este caso es que, si bien hubo una caída en el número de hogares que no reciben ingresos, la reducción fue menor que en los demás tipos de viviendas y, al contrario del resto, el promedio de perceptores de ingresos aumentó respecto del promedio que se declaró como trabajadores; también en este tipo de viviendas es donde se presenta el mayor porcentaje de trabajadores por cuenta propia y junto con las viviendas en colonias prioritarias hay una mayor proporción de trabajadores en empresas privadas. 
Tijuana ante el confinamiento social impuesto por la covID-19: habitabilidad de las viviendas, entorno urbano y condiciones económicas en los hogares

Cuadro 15. Condiciones y problemáticas económicas de los hogares

\begin{tabular}{|c|c|c|c|c|c|c|}
\hline \multirow[t]{2}{*}{ Indicador } & \multicolumn{2}{|c|}{$\begin{array}{l}\text { Tipo de } \\
\text { colonias }\end{array}$} & \multicolumn{3}{|c|}{ Tipo de viviendas } & \multirow[b]{2}{*}{$\frac{\mathscr{\Xi}}{\widetilde{\Xi}}$} \\
\hline & 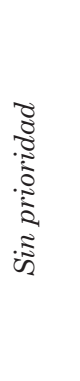 & 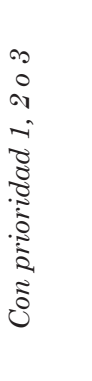 & 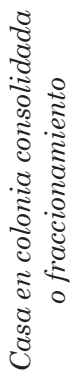 & 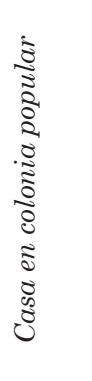 & 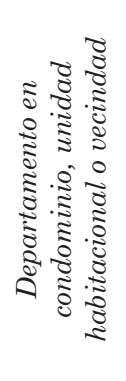 & \\
\hline $\begin{array}{l}\text { Porcentaje de hogares con algún } \\
\text { miembro que trabaja }\end{array}$ & 96.1 & 100.0 & 97.3 & 97.3 & 95.6 & 97.0 \\
\hline $\begin{array}{l}\text { Promedio de trabajadores en } \\
\text { hogares en donde al menos un } \\
\text { miembro trabaja }\end{array}$ & 1.80 & 1.81 & 1.80 & 1.89 & 1.77 & 1.80 \\
\hline \multicolumn{7}{|l|}{ Porcentaje de trabajadores en: } \\
\hline Empresa privada & 44.9 & 57.8 & 47.9 & 54.1 & 43.5 & 48.0 \\
\hline Por cuenta propia & 28.5 & 20.3 & 26.1 & 32.4 & 23.9 & 26.6 \\
\hline Empresa familiar & 9.2 & 6.3 & 9.6 & 2.7 & 8.7 & 8.5 \\
\hline Organización social & 5.8 & 6.3 & 4.8 & 2.7 & 13.0 & 5.9 \\
\hline Gobierno & 22.7 & 20.3 & 23.4 & 21.6 & 17.4 & 22.1 \\
\hline Servicios de salud & 5.3 & 0.0 & 4.3 & 2.7 & 4.3 & 4.1 \\
\hline Educación pública & 19.8 & 15.6 & 21.3 & 16.2 & 10.9 & 18.8 \\
\hline Educación privada & 7.7 & 6.3 & 8.5 & 5.4 & 4.3 & 7.4 \\
\hline $\begin{array}{l}\text { Porcentaje de hogares con algún } \\
\text { miembro que percibe un ingreso }\end{array}$ & 86.9 & 89.1 & 87.2 & 91.9 & 84.8 & 87.5 \\
\hline $\begin{array}{l}\text { Promedio de miembros del que } \\
\text { perciben un ingreso en hogares con } \\
\text { ingresos actuales }\end{array}$ & 1.68 & 1.65 & 1.64 & 1.94 & 1.56 & 1.67 \\
\hline \multicolumn{7}{|l|}{ Problemas para pagar: } \\
\hline La hipoteca de la viviendas* & 27.6 & 37.5 & 29.7 & 33.3 & 25.0 & 29.7 \\
\hline Renta de la vivienda* & 17.8 & 62.5 & 25.0 & 60.0 & 15.6 & 23.0 \\
\hline Créditos o deudas & 27.5 & 40.6 & 28.2 & 32.4 & 39.1 & 30.6 \\
\hline Colegiaturas & 7.7 & 14.1 & 8.5 & 10.8 & 10.9 & 9.2 \\
\hline Servicios & 15.9 & 23.4 & 14.4 & 37.8 & 15.2 & 17.7 \\
\hline Cuota de mantenimiento & 5.3 & 4.7 & 5.9 & 2.7 & 4.3 & 5.2 \\
\hline $\begin{array}{l}\text { Porcentaje de hogares que ha } \\
\text { tenido al menos un problema } \\
\text { económico }\end{array}$ & 51.2 & 67.2 & 52.1 & 62.2 & 60.9 & 55.0 \\
\hline
\end{tabular}

Sociedad No.78-79 
* Estas variables se calcularon considerando solo el subconjunto de hogares que habitan viviendas que son propias pero aún se están pagando, o que son rentadas.

Fuente: Elaboración propia con información de UNAM-IIS (2020) y Sánchez, Morales y Lares (2020b).

Los problemas laborales y de ingresos han puesto al $55 \%$ de las familias estudiadas en aprietos económicos, de las cuales más del 30\% manifestó tener dificultades para el pago de créditos o deudas y casi el 18\% para el pago de servicios; dentro de los grupos que rentan su vivienda o la tienen hipotecada el $23 \%$ y casi el $28 \%$, respectivamente, manifestaron tener problemas para seguir pagando estos compromisos. En el interior de los diferentes subconjuntos de viviendas se observa que los problemas económicos afectan en mucha mayor medida a los hogares que habitan en colonias populares y colonias prioritarias, en las cuales el porcentaje de hogares con dificultades de pago ronda las dos terceras partes y, con excepción de las cuotas de mantenimiento, los problemas para cumplir con varios rubros son superiores al promedio general, especialmente en lo que se refiere al pago de renta, servicios, hipotecas y deudas o créditos. En este último tipo de adeudos los residentes de los departamentos también manifiestan tener dificultades en altas proporciones.

Los datos anteriores indican que muchas familias enfrentan un doble problema: la pérdida de ingresos y dificultades para el pago de compromisos contraídos con anterioridad, que en conjunto podrían marginarlos en el corto plazo del acceso a servicios básicos y en el futuro complicarles su situación financiera. 
Tijuana ante el confinamiento social impuesto por la coviD- 19: habitabilidad de las viviendas, entorno urbano y condiciones económicas en los hogares

\section{A manera de conclusión: la acción de los gobiernos locales y las propuestas ciudadanas}

Si bien es cierto los gobiernos locales han emprendido de acciones para atender diversas problemáticas derivadas de la pandemia, existen pocas que están dirigidas a resolver o atenuar problemáticas de las familias ante el confinamiento. En el caso del gobierno estatal, la mayor parte de las acciones emprendidas tiene como principal beneficiario a las empresas, principalmente pequeñas y medianas, y solo uno de los once programas puestos en marcha en el marco de la pandemia está orientado a población vulnerable con el otorgamiento de despensas. ${ }^{6}$ Por su parte, el Congreso del estado aprobó una reforma al Código Civil para posibilitar la suspensión de pagos en arrendamiento de vivienda y locales comerciales, durante abril y mayo, pero estableció que dicha acción no libera de estos pagos a los arrendatarios, ya que deberán distribuir los montos en los siguientes meses y, en caso de conflicto, deberán acudir a los jueces o centros de justicia alternativa para llegar a un acuerdo (Poder Legislativo Estatal, 2020). Las acciones del Ayuntamiento de Tijuana se han enfocado, en lo que toca al confinamiento y el uso del espacio público, a suspender eventos públicos, sanitizar espacios y transportes públicos y proveer ayuda para la educación a distancia. Por su parte, la sociedad civil, la iniciativa privada y la UABC han desarrollado iniciativas que complementan las acciones gubernamentales en la sanitización de espacios y transportes, así como en la atención psicológica.

Quizá debido a esta débil intervención gubernamental, los resultados del cuestionario mostraron altos niveles de desaprobación y de desconocimiento de las acciones emprendidas por el estado y el municipio ante la pandemia. Para ambos

6. Los programas del Gobierno de Baja California pueden consultarse en CIDE (2020). 
gobiernos la desaprobación y el desconocimiento ronda el $64 \%$; si bien la federación tiene una nota desaprobatoria y de desconocimiento menor (56.4\%), no deja de ser significativa. Ante este panorama, quienes respondieron el cuestionario realizaron 271 propuestas de lo que en su opinión debería hacer el gobierno para mejorar las condiciones frente al confinamiento, las cuales clasificamos en ocho categorías, que van desde apoyos económicos hasta la aplicación medidas punitivas extremas para garantizar el confinamiento. Como puede apreciarse en el cuadro siguiente, la mayoría de las propuestas están orientadas a tres categorías: a) apoyos de tipo económico, tanto para empresas como para familias, así como para la vigilancia en el cumplimiento del cierre de empresas no esenciales; b) acciones para obligar o concientizar sobre la necesidad del "quédate en casa", y c) medidas para mejorar la calidad de la información, para hacerla llegar a públicos más amplios y para la unificación de mensajes en el interior del gobierno federal y con los otros dos órdenes de gobierno.

Cuadro 16. Propuestas para mejorar los efectos del "quédate en casa" por parte del gobierno según distintas categorías

\begin{tabular}{ccc}
\hline Categoría & Cantidad & $\%$ \\
\hline $\begin{array}{c}\text { Económico: apoyos a pymes, servicios, alquileres, } \\
\text { ingresos, cierre de empresas }\end{array}$ & 73 & 26.9 \\
$\begin{array}{c}\text { Aislamiento social: ser más estrictos, multar a } \\
\text { quien no se quede en casa, restringir la movilidad y } \\
\quad \text { promover quedarse en casa }\end{array}$ & 67 & 24.7 \\
$\begin{array}{c}\text { Información: credibilidad de la información, más } \\
\text { información y unificación de mensajes }\end{array}$ & 45 & 16.6 \\
$\begin{array}{c}\text { Salud: apoyo a hospitales y aplicación de más } \\
\text { pruebas }\end{array}$ & 22 & 8.1 \\
$\begin{array}{c}\text { Sociales: cuidado adultos mayores, niños y grupos } \\
\text { vulnerables, apoyos alimentarios }\end{array}$ & 17 & 6.3 \\
$\quad$ Seguridad: toque de queda, aplicar la ley & 14 & 5.2 \\
\hline
\end{tabular}


Tijuana ante el confinamiento social impuesto por la covID-19: habitabilidad de las viviendas, entorno urbano y condiciones económicas en los hogares

\begin{tabular}{ccc}
\hline Categoría & Cantidad & $\%$ \\
\hline $\begin{array}{c}\text { Educación en línea: ofrecer Internet gratuito, } \\
\text { cursos y talleres en línea y en televisión }\end{array}$ & 8 & 3.0 \\
$\begin{array}{c}\text { Otras propuestas: está bien lo que se hace, nada, } \\
\text { organizar comités de vecino, alianzas con osc, } \\
\quad \text { etcétera }\end{array}$ & 25 & 9.2 \\
\hline
\end{tabular}

Fuente: Elaboración propia con información de UNAM-IIS (2020).

A partir de las propuestas anteriores, a continuación se presenta una selección de las que, a nuestro juicio, son las mejores por su claridad y posición constructiva. Es posible advertir que las acciones a instrumentar exigirán en algunos casos la participación concertada de los tres órdenes de gobierno, y en otros al menos la colaboración de los gobiernos estatales y municipales.

\section{Cuadro 17. Mejores propuestas para mejorar los efectos del "quédate en casa" por parte del gobierno}

\begin{tabular}{|c|c|}
\hline Categoría & Propuestas \\
\hline Económico & $\begin{array}{c}\text { Establecer un plan factible de recuperación económica y } \\
\text { movilidad con seguridad posterior al levantamiento de } \\
\text { la cuarentena } \\
\text { Proporcionar una renta básica o crear un seguro de } \\
\text { desempleo }\end{array}$ \\
\hline Sociales & Un plan de apoyo a las comunidades más vulnerables \\
\hline \multirow[t]{4}{*}{ Salud } & $\begin{array}{c}\text { Realizar mayor cantidad pruebas para detectar zonas } \\
\text { de alto o mediano riesgo }\end{array}$ \\
\hline & $\begin{array}{c}\text { Proveer mascarillas, guantes, gel antibacterial y viseras } \\
\text { para evitar contagios y poder salir }\end{array}$ \\
\hline & $\begin{array}{c}\text { Apoyo psicológico para niños, madres, padres, viejos } \\
\text { Reforzar sistema de salud pública }\end{array}$ \\
\hline & $\begin{array}{c}\text { Sanitización de lugares públicos y regulación sanitaria } \\
\text { en todas las actividades que involucren presencia de } \\
\text { más de } 50 \text { personas }\end{array}$ \\
\hline $\begin{array}{l}\text { Aislamiento } \\
\text { social }\end{array}$ & Implementar filtros en algunas zonas de la ciudad \\
\hline
\end{tabular}




\begin{tabular}{cc}
\hline Categoría & Propuestas \\
\hline Información & $\begin{array}{r}\text { Mejorar la comunicación, hacerla más efectiva y } \\
\text { comprensible. No politizar el tema }\end{array}$ \\
& Campañas de corresponsabilidad de la vida familiar \\
Educación en & $\begin{array}{r}\text { Evitar que los sistemas educativos sigan el mismo } \\
\text { programa que tendrían en el aula }\end{array}$ \\
& $\begin{array}{c}\text { Proporcionar Internet a las familias de escasos recursos } \\
\text { para que los estudiantes puedan hacer sus tareas a } \\
\text { distancia }\end{array}$ \\
Urbano & $\begin{array}{c}\text { En hogares con hacinamiento habilitar espacios de } \\
\text { esparcimiento en los que se puedan hacer actividades } \\
\text { manteniendo la sana distancia }\end{array}$ \\
\hline
\end{tabular}

Fuente: Elaboración propia con información de UNAM-IIS (2020).

Considerando que los gobiernos locales tienen facultades para intervenir en diversos campos de acción referentes a la aplicación o el desarrollo de medidas para mitigar problemas vinculados a la pandemia y al confinamiento, se sugiere que participen más activamente en la vigilancia del cumplimiento de las restricciones sanitarias; uso, sanitización y desinfección de espacios públicos; desarrollo e implementación de campañas de información y concientización orientadas a problemáticas y públicos específicos; implementación de un plan de apoyo a las comunidades más vulnerables; determinación de zonas de alto y mediano riesgo a la Covid (como ya sucede en la Ciudad de México,; así como promoción de una convivencia vecinal más solidaria y responsable. Lo anterior no elimina su responsabilidad de exigir a la federación que desarrolle la infraestructura necesaria y otorgue los insumos y personal médico que permita enfrentar la pandemia con el propósito de ofrecer los cuidados que requieran las personas contagiadas y se reduzca sensiblemente la tasa de letalidad en la ciudad, que resulta una de las más alta del país.

\section{6}


Alegría, T. y G. Ordóñez, 2005. Legalizando la ciudad.AsentaBibliografía mientos informales y procesos de regularización en Tijuana. México: COLEF.

CIDE (2020). Federalismo en COVID. Plataforma interactiva sobre políticas estatales ante la pandemia por covid-19. Disponible en: https://www.cide.edu/coronavirus/federalismo-covid/.

Conferencia Interamericana de Seguridad Social (CISS) (2020). Plataforma coviD-19. Datos CoviD-19: OMs, última actualización: 9-7-20. Disponible en: https://ciss-bienestar.org/ plataforma_covid I 9/index.html.

CONAPO (2016). Índice de marginación por entidad federativa y municipio 20 15. México: CONAPO. Disponible en: https:// www.academia.edu/29482485/\%C3\%8Dndice_de_marginaci\%C3\%B3n_por_entidad_federativa_y_municipio_20I5.

(2020). Proyecciones de la Población de México y de las Entidades Federativas, 2016-2050. Disponible en: https://datos.gob.mx/busca/dataset/proyecciones-de-la-poblacion-de-mexico-y-de-las-entidades-federativas-2016-2050.

CONeVAl (2015). Medición de la pobreza. Anexo estadístico de pobreza a nivel municipal, 2010 y 2015. Disponible en: https://www.coneval.org.mx/Medicion/Paginas/ AE_pobreza_municipal.aspx.

(20I7). CONEVAL informa la evolución de la pobreza 20I02016. Comunicado de prensa núm. 9 (30 de agosto). Disponible en: https://www.coneval.org.mx/SalaPrensa/ Comunicadosprensa/Documents/Comunicado-09-Medicion-pobreza-2016.pdf.

Consejo de Salubridad General (2020). “Acuerdo por el que se declara como emergencia sanitaria por causa de fuerza mayor, a la epidemia de enfermedad generada por el virus Sars-Cov2 (CovID-19)”. México: Diario Oficial de 
la Federación, 30 de marzo. Disponible en: https://dof. gob.mx/2020/CSG/CSG_300320_VES.pdf.

Friedman, J.; Calderón,A.; Bojorquez, I.;Vera, C.; Schriger, D. y E.Tovar (2020)."Excess Out-of-Hospital Mortality and Declining Oxygen Saturation:The Sentinel Role of EMS Data in the CovID-19 Crisis in Tijuana, Mexico", medRxiv preprint Dol:https://doi.org/I0.1 I0I/2020.05.13.20098 186. This version posted May 19, 2020.

Gobierno de México (2020). Covid-1 9 México. Disponible en: https://coronavirus.gob.mx/datos/.

INEGI (20I4). Características de las localidades y del entorno urbano 20/4. Disponible en: https://www.inegi.org.mx/ programas/cleu/20I4/default.html?init=2.

- (2015). Tabulados de la Encuesta Intercensal 2015. Disponible en: https://www.inegi.org.mx/programas/ intercensal/20I5/default.html\#Tabulados.

(2020). Visualizador analítico para el covid-19. Disponible en: https://gaia.inegi.org.mx/ covid I9/.

Instituto Metropolitano de Planeación de Tijuana (IMPLAN), 20 I 4. Mapa básico por delegaciones 20/4/Colonias 20 / 4. Disponible en: https://www.implantijuana.org/servicios/ cartografia/.

Ordóñez, G. (2020). “Tijuana: Condiciones de habitabilidad y confinamiento social por covID-19”. En A. Ziccardi (Coord.), Habitabilidad, entorno urbano y distanciamiento social. Una investigación en ocho ciudades mexicanas ante COVID 19. México: UNAM-IIS (en dictamen)

Pérez, A. (2020). "Transmisión con la información actualizada de la salud de Baja California (I 3 de julio de 2020, minutos II:59 y I5:19-12:00)". Disponible en: https://www.facebook.com/JaimeBonillaValdez/ videos/ I I 20839368293502.

Poder Legislativo Estatal (2020).“Decreto núm. 54 mediante el cual se reforma el artículo 1986 del Código Civil para 
el estado de Baja California", Periódico Oficial de Estado Bibliografía de Baja California, Mexicali, México (3 de abril de 2020). Sánchez, R.; Morales, E.y F. Lares (2020a). Vulnerabilidad social al COVID-19 en Baja California. El COLef, documento de contingencia 3.Tijuana, México.

(2020b). Vulnerabilidad social al covid-1 9 enTijuana, Baja California (versión 2). El COLEF, documento de política. Tijuana, México.

Secretaría de Salud (2020a). Jornada Nacional de Sana Distancia. Disponible en: https://www.gob.mx/salud/documentos/sana-distancia.

(2020b).“Acuerdo por el que se establecen acciones extraordinarias para atender la emergencia sanitaria generada por el virus sars-cov2”. México, Diario Oficial de la Federación (3I de marzo). Disponible en: https:// www.dof.gob.mx/nota_detalle.php?.codigo $=55909$ |4\&fecha $=3 \mathrm{l} / 03 / 2020$.

(2020c). "Acuerdo por el que se establecen los Lineamientos técnicos específicos para la reapertura de las actividades económicas”. México, Diario Oficial de la Federación (29 de mayo). Disponible en: https:// www.dof.gob.mx/nota_detalle.php?.codigo $=55909$ | $4 \&$ fecha=3l/03/2020.

Universidad Nacional Autónoma de México-Instituto de Investigaciones Sociales (UNAM-IIS) (2020). Base de datos del cuestionario "Condiciones de habitabilidad de las viviendas y del entorno urbano ante el aislamiento social impuesto por COVID 19".

Ziccardi, A. et al. (2020). Informe preliminar "Condiciones de habitabilidad de las viviendas y del entorno urbano ante el aislamiento social impuesto por covid 19", I I de mayo. Disponible en: https://www.iis.unam.mx/wp-content/ uploads/2020/05/CONDICIONES-DE-HABITABILIDAD.pdf. 